\title{
ARL13B, a Joubert Syndrome-Associated Protein, Is Critical for Retinogenesis and Elaboration of Mouse Photoreceptor Outer Segments
}

\author{
Tanya L. Dilan, ${ }^{1,2}$ - Abigail R. Moye, ${ }^{1,2 *}$ Ezequiel M. Salido, ${ }^{1 *}$ Thamaraiselvi Saravanan, ${ }^{1}$ Saravanan Kolandaivelu, ${ }^{1,2}$ \\ (1)Andrew F.X. Goldberg, ${ }^{4}$ and Visvanathan Ramamurthy ${ }^{1,2,3}$ \\ ${ }^{1}$ Department of Ophthalmology and Neuroscience, ${ }^{2}$ Department of Biochemistry, ${ }^{3}$ WVU Rockefeller Neuroscience Institute, West Virginia University, \\ Morgantown, West Virginia 26506, and ${ }^{4}$ Eye Research Institute, Oakland University, Rochester, Michigan 48309
}

Mutations in the Joubert syndrome-associated small GTPase ARL13B are linked to photoreceptor impairment and vision loss. To determine the role of ARL13B in the development, function, and maintenance of ciliated photoreceptors, we generated a pan-retina knock-out (Six3-Cre) and a rod photoreceptor-specific inducible conditional knock-out (Pde6g-Cre ${ }^{\text {ERT2 }}$ ) of ARL13B using murine models. Embryonic deletion of ARL13B led to defects in retinal development with reduced cell proliferation. In the absence of ARL13B, photoreceptors failed to develop outer segment $(\mathrm{OS})$ membranous discs and axonemes, resulting in loss of function and rapid degeneration. Additionally, the majority of photoreceptor basal bodies did not dock properly at the apical edge of the inner segments. The removal of ARL13B in adult rod photoreceptor cells after maturation of OS resulted in loss of photoresponse and vesiculation in the OS. Before changes in photoresponse, removal of ARL13B led to mislocalization of rhodopsin, prenylated phosphodiesterase-6 (PDE6), and intraflagellar transport protein-88 (IFT88). Our findings show that ARL13B is required at multiple stages of retinogenesis, including early postnatal proliferation of retinal progenitor cells, development of photoreceptor cilia, and morphogenesis of photoreceptor OS discs regardless of sex. Last, our results establish a need for ARL13B in photoreceptor maintenance and protein trafficking.

Key words: blindness; IFT; Joubert syndrome; outer segment; photoreceptors; protein trafficking

Significance Statement

The normal development of photoreceptor cilia is essential to create functional, organized outer segments with stacked membrane discs that house the phototransduction proteins necessary for sight. Our study identifies a complex role for ARL13B, a small GTPase linked to Joubert syndrome and visual impairment, at various stages of photoreceptor development. Loss of ARL13B led to defects in retinal proliferation, altered placement of basal bodies crucial for components of the cilium (transition zone) to emanate, and absence of photoreceptor-stacked discs. These defects led to extinguished visual response and dysregulated protein trafficking. Our findings show the complex role ARL13B plays in photoreceptor development, viability, and function. Our study accounts for the severe retinal impairment observed in ARL13B-linked Joubert syndrome patients.

\section{Introduction}

ADP ribosylation factor-like GTPase $13 \mathrm{~B}($ Arl13b) is a member of the Arf-like Ras superfamily of small GTPases. Small GTPases

Received July 11, 2018; revised Nov. 16, 2018; accepted Dec. 12, 2018.

Author contributions: T.L.D. wrote the first draft of the paper; T.L.D., A.R.M., A.F.X.G., and V.R. edited the paper; T.L.D., A.F.X.G., and V.R. designed research; T.L.D., A.R.M., E.M.S., T.S., S.K., and A.F.X.G. performed research; T.L.D., E.M.S., and V.R. analyzed data; T.L.D. and V.R. wrote the paper.

This work was supported by the National Institutes of Health (Grants R01 EY028035, R01 EY025536, and R21 EY027707) and the West Virginia Lions and Lions Club International Foundation. We thank Tamara Caspary (Emory) and Peter Mathers (WVU) for providing the animals used in this study; Mike Schaller for aiding in the preparation of this manuscript; and Victoria Kimler (Eye Research Institute, Oakland University) and Mateo Dilan (WVU) for help with data collection.

The authors declare no competing financial interests.

${ }^{*}$ A.R.M. and E.M.S. contributed equally to this work. serve as molecular "switches" that cycle between GDP-bound "off" and GTP-bound "on" conformations (Cherfils and Zeghouf, 2013). In their GTP-bound conformation, also known as the active state, small GTPases elicit a wide variety of cellular responses by binding to different effector proteins (Bishop and Hall, 2000; Cherfils and Zeghouf, 2013). ARL13B is a larger protein among the Arf/Arl family of small GTPases and lacks a highly conserved glutamine residue that is critical for the protein's intrinsic GTPase activity (Hori et al., 2008; Miertzschke et al.,

Correspondence should be addressed to Visvanathan Ramamurthy at ramamurthyv@wvumedicine.org. https://doi.org/10.1523/JNEUROSCI.1761-18.2018

Copyright $\odot 2019$ the authors $\quad 0270-6474 / 19 / 391347-18 \$ 15.00 / 0$ 
2014; Ivanova et al., 2017). Additionally, ARL13B is doubly palmitoylated at the $\mathrm{N}$-terminal region of the protein and it is highly enriched within the cilium, a microtubule-based organelle protrusion that acts as a signaling hub for the extracellular environment (Caspary et al., 2007; Cevik et al., 2010; Malicki and Johnson, 2017). The aforementioned lipid modification plays a critical role in ARL13B's ciliary localization, stability, and function (Roy et al., 2017).

Mutations in the Arl13b gene are linked to Joubert syndrome, an autosomal-recessive "ciliopathy" characterized by hypotonia, ataxia, intellectual disability, obesity, and retinal dystrophy (Cantagrel et al., 2008; Thomas et al., 2015). Moreover, removal of Arl13b leads to defective ciliogenesis in the kidney duct of zebrafish models and in murine renal epithelia (Sun et al., 2004; Li et al., 2016). In mice, a null allele of Arl13b (hennin mutant) leads to embryonic lethality, markedly shorter nodal cilia, and structural defects in the ciliary axoneme (Caspary et al., 2007). Interestingly, ARL13B is needed for the formation of the eye, with hennin mutant embryos exhibiting traits of anophthalmia (Caspary et al., 2007). Previous studies have reported that ARL13B acts as a ciliary length regulator by its unique ability to induce ciliary membrane protrusions (Larkins et al., 2011; Lu et al., 2015). However, the role of ARL13B in axonemal extension, a process critical for cilia formation, remains unclear.

In addition to its role in the development of cilia, ARL13B is a guanine-nucleotide exchange factor (GEF) that activates ARL3, another small GTPase (Gotthardt et al., 2015; Zhang et al., 2016). Mutations in the ARL3 gene are linked to retinitis pigmentosa (vision loss) in humans (Strom et al., 2016). Recent studies in which either ARL3 is ablated or a GTP-locked mutant form of ARL3 is expressed in rod photoreceptors suggest that ARL3, through its interaction with PRBP $\delta$ and UNC119, binds prenylated and myristoylated protein cargoes, respectively, and aids in their trafficking (Ismail et al., 2012; Ivanova et al., 2017). (HankeGogokhia et al., 2016; Wright et al., 2016). Defects in ARL3 led to mistrafficking of prenylated phosphodiesterase-6 (PDE6), as well as accumulation of lipidated transducin in the photoreceptor inner segment (IS) (Hanke-Gogokhia et al., 2016; Wright et al., 2016). Additionally, these animals suffered from progressive loss of photoreceptor cells (Hanke-Gogokhia et al., 2016; Wright et al., 2016). The critical role of ARL3 in transport of lipidated photoreceptor outer segment (OS) proteins points to a likely important role for its GEF, ARL13B, in these processes. Therefore, to better understand the role of ARL13B in trafficking of lipidated proteins and in photoreceptor development, in this study, we conditionally ablated ARL13B in the developing retina and selectively removed ARL13B in mature rod photoreceptor cells.

\section{Materials and Methods}

Mice, genotyping, and animal husbandry. The Arl13b flx/flx line, which contains LoxP sites flanking exon 2, was backcrossed with C57BL/6J mice (The Jackson Laboratory, Stock No. 000664) for five generations. Arl13b $b^{\text {flx/flx }}$ animals were then crossed with Six3-cre or Pde6g-Cre ${ }^{\text {ERT2 }}$ to generate retina-specific (Six3-Cre) and rod-specific conditional ablation of Arl13b (Furuta et al., 2000; Su et al., 2012). All experiments used littermates as controls. For inducible deletion of Arl13b in rod photoreceptors using the $P d e 6 g$-Cre ${ }^{\text {ERT2 }}$ line, tamoxifen (Sigma-Aldrich catalog \#T5648-1G) was injected intraperitoneally at concentrations of $100 \mu \mathrm{g} / \mathrm{g}$ body weight for 3 consecutive days ( 1 injection/d) as described previously (Koch et al., 2015). PCR primers used to detect floxed alleles were 5' -CGA CCA TCA CAA GTG TCA CC-3' and 5' -AGG ACG GTT GAG AAC CAC TG- $3^{\prime}$. Oligonucleotides used in PCR to detect Cre recombinase were $5^{\prime}$-CCT GGA AAA TGC TTC TGT CCG-3' and 5' -CAG GGT GTT ATA AGC AAT CCC- $3^{\prime}$. Oligonucleotides used in PCR to verify the presence of $P d e 6 g$-Cre ${ }^{\text {ERT2 }}$ driver line were 5 '-GGT CAG ATT CCA GTG TGT GG-3' and 5'-GTT TAG CTG GCC CAA ATG TTG-3'. All animals used in this study are free of $r d 1$ and $r d 8$ alleles (Giménez and Montoliu, 2001; Mattapallil et al., 2012).

The animals were maintained under $12 \mathrm{~h}$ light/12 h dark light cycles with food and water provided ad libitum. All experimental procedures involving animals in this study were approved by the Institutional Animal Care and Use Committee of West Virginia University.

Electroretinography (ERG). ERGs were performed on the UTAS Visual Diagnostic System Big-Shot Ganzfeld using a UBA-4200 amplifier and interface, and EMWIN 9.0.0 software (LKC Technologies). Before ERG testing, mice were dark-adapted for $24 \mathrm{~h}$. Mice were anesthetized [2.0\% isoflurane with 2.5 liters per minute (lpm) oxygen flow rate] for $10 \mathrm{~min}$ and eyes were topically dilated with a 1:1 mixture of tropicamide: phenylephrine hydrochloride. For the ERG procedure, mice were placed on a heated platform with continuous flow of isoflurane through a nose cone (1.5\% isoflurane with $2.5 \mathrm{lpm})$. A reference electrode was introduced subcutaneously in the scalp and ERG responses were recorded from both eyes with silver wire electrodes placed on top of each cornea, with contact being facilitated with hypromellose solution (2\% hypromellose in PBS; Gonioscopic Prism Solution; Wilson Ophthalmic). Scotopic photoresponses were acquired under dark conditions with flashes of LED white light at increasing flash intensities. For photopic photoresponses, animals were light-adapted with rod-saturating white background light (30 $\mathrm{cd} / \mathrm{m}^{2}$ ) for $10 \mathrm{~min}$ and cone photoresponses were subsequently recorded.

Immunohistochemistry. For immunohistochemical experiments, eyes were enucleated and immersed in $4 \%$ paraformaldehyde fixative ( $4 \%$ PFA in PBS containing $137 \mathrm{~mm} \mathrm{NaCl}, 2.7 \mathrm{~mm} \mathrm{KCl}, 4.3 \mathrm{~mm}$ $\mathrm{Na}_{2} \mathrm{HPO}_{4} \cdot 7 \mathrm{H}_{2} \mathrm{O}$, and $1.4 \mathrm{mM} \mathrm{KH} \mathrm{PO}_{4}$ for 30 min before the removal of the cornea and lens. Following removal of cornea and lens, enucleated eyes were fixed for an additional $30 \mathrm{~min}$, washed in PBS 3 times for $5 \mathrm{~min}$ each, and incubated in $20 \%$ sucrose in PBS overnight at $4^{\circ} \mathrm{C}$ on a nutator. Following overnight incubation, eyecups were placed in a 1:1 mixture of $20 \%$ sucrose in PBS and Cryo Optimal Cutting Temperature (OCT) Compound (Sakura) for $1 \mathrm{~h}$ and flash-frozen in OCT. For ciliary staining, enucleated eyes were fixed in 4\% PFA in PBS for $30 \mathrm{~s}$ and flash-frozen in OCT. Cryosectioning was performed using Leica CM1850 Cryostat and retinal sections of $16 \mu \mathrm{m}$ and/or $12 \mu \mathrm{m}$ (for ciliary staining) thickness were mounted on Superfrost Plus slides (Fisher Scientific). Mounted retinal sections were washed with PBST (PBS with 5\% goat sera, $0.5 \%$ Triton X-100, and $0.05 \%$ sodium azide) 2 times for 5 min each and incubated for $1 \mathrm{~h}$ in blocking buffer at room temperature (PBST: PBS with $5 \%$ goat sera, $0.5 \%$ Tween 20 , and $0.05 \%$ sodium azide). After blocking, retinal sections were incubated with primary antibodies at the dilutions described in Table 1 at $4^{\circ} \mathrm{C}$ overnight. For ciliary staining, incubation with primary antibodies was done for $3-4 \mathrm{~h}$ at room temperature. After primary antibody incubation, retinal sections were washed with PBST 2 times for $5 \mathrm{~min}$ and once with PBS for $5 \mathrm{~min}$ before incubation with secondary antibodies (anti-rabbit 488 or 568, anti-mouse 488 or 568 , anti-guinea pig 680 , anti-chicken 488 ) for $1 \mathrm{~h}$. Nuclei were stained with DAPI nuclear stain 405 . Slides were mounted with ProLong Gold (Life Technologies) and coverslipped. Confocal imaging was performed with the Nikon C2si+ system laser-scanning confocal microscope using excitation wavelengths of 405, 488, 543, and $647 \mathrm{~nm}$. Micrographs were captured using the same exposure time settings among all groups.

Immunoblotting. Mice were killed by $\mathrm{CO}_{2}$ inhalation followed by cervical dislocation. Eyes were enucleated and retinas were dissected following previously established protocols (Ramamurthy et al., 2004). For immunoblots, flash-frozen retinas were sonicated in PBS with protease inhibitor mixture (Roche). Protein concentrations were measured using a spectrophotometer (Thermo Fisher Scientific) and the RC DC protein assay (Bio-Rad Laboratories). Equal amounts of samples (100 $\mu \mathrm{g}$ of total protein per well) were separated in a polyacrylamide SDS-PAGE gel and transferred onto polyvinylidene difluoride (PVDF) membranes (Immobilon-FL; Millipore). Membranes were subsequently incubated in blocking buffer (Odyssey Blocking Buffer; LI-COR Biosciences) for $45 \mathrm{~min}$ at 
Table 1. List of antibodies used in this study

\begin{tabular}{|c|c|c|}
\hline Antibody & Source & Dilution \\
\hline Rabbit anti-PDE6 $\beta$ & Thermo Fisher PA1-722 & $1: 2000$ \\
\hline Mouse anti-GAPDH & Fitzgerald 10R-G109a & $1: 10,000$ \\
\hline Mouse anti-GRK1 & Thermo Fisher MA1-720 & $1: 2000$ \\
\hline Mouse anti-CNGA1 & $\begin{array}{l}\text { UC Davis/NIH NeuroMab Facility } \\
\text { \#L36-12 }\end{array}$ & 1:1000 \\
\hline Chicken anti-RP1 & $\begin{array}{l}\text { Gift from Dr. Eric Pierce, Ocular } \\
\text { Genomics Institute, Harvard } \\
\text { University }\end{array}$ & $1: 500$ \\
\hline Mouse anti-acetylated tubulin & Santa Cruz 6-11B-1 & $1: 500$ \\
\hline $\begin{array}{l}\text { Mouse anti-glutamylated } \\
\text { tubulin }\end{array}$ & $\begin{array}{l}\text { AdipoGen LifeSciences AG-20B- } \\
\text { 0020B-C100 }\end{array}$ & $1: 500$ \\
\hline Mouse anti-beta tubulin & Sigma T8328 & $1: 4000$ \\
\hline Guinea pig anti-MAK & Wako 012-26441 & $1: 500$ \\
\hline Chicken anti-Rootletin & $\begin{array}{l}\text { Gift from Dr. Tiansen Li, National } \\
\text { Eye Institute }\end{array}$ & $1: 500$ \\
\hline Mouse anti-ARL13B & NeuroMab N295B/66 & $1: 500$ \\
\hline Rabbit anti-RDS-c (Peripherin) & $\begin{array}{l}\text { Gift from Dr. Gabriel Travis, } \\
\text { University of California, Los } \\
\text { Angeles, CA }\end{array}$ & $1: 2000$ \\
\hline Mouse anti-1D4 (Rhodopsin) & $\begin{array}{l}\text { Gift from Dr. Ted Wensel, Baylor } \\
\text { College of Medicine }\end{array}$ & $1: 500$ \\
\hline $\begin{array}{l}\text { 4ל,6-diamindino-2-phenylin- } \\
\text { dole, (DAPI) }\end{array}$ & Invitrogen & $1: 1000$ \\
\hline Propidium lodide & EMD Millipore, Billerica, MA, USA & $1: 2000$ \\
\hline $\begin{array}{l}\text { Rabbit anti-Phospho-his- } \\
\text { toneH3 (pHH3) }\end{array}$ & Cell Signaling \#9701 & 1:1000 \\
\hline Mouse anti-Ki-67 & BD Pharmagen \#550609 & 1:1000 \\
\hline Rabbit anti-IFT88 & $\begin{array}{l}\text { Gift from Dr. Gregory Pazour, } \\
\text { Univ. of Massachusetts }\end{array}$ & 1:500 \\
\hline Mouse anti-GalphaT1 & Santa Cruz \#136143 & 1:5000 \\
\hline CytC & Santa Cruz \#13561 & $1: 2000$ \\
\hline Goalpha & Santa Cruz \#13532 & $1: 2000$ \\
\hline PRCD & Gift from Dr. Kolandaivelu (WVU) & 1:1000 \\
\hline $\begin{array}{l}\text { Rabbit anti-Na,K-ATPase Beta } \\
2 \text { subunit }\end{array}$ & Gift from Dr. Kolandaivelu (WVU) & $1: 2000$ \\
\hline Rabbit anti-AIPL1 & Custom-generated & 1:1000 \\
\hline $\mathrm{GC}-1$ & $\begin{array}{l}\text { Gift from Dr. James Hurley, Univ. } \\
\text { of Washington }\end{array}$ & $1: 1000$ \\
\hline ATP1 $\beta 2$ & Proteintech 22338-I-AP & 1:1500 \\
\hline Centrin & Abcam ab4448 & $1: 1000$ \\
\hline
\end{tabular}

room temperature and further incubated with primary antibodies overnight at $4^{\circ} \mathrm{C}$ on a bidirectional rotator. Following primary antibody incubation (Table 1), membranes were washed in PBST (PBS with $0.1 \%$ Tween 20) 3 times for 5 min each at room temperature and incubated in secondary antibody, goat anti-rabbit Alexa Fluor 680 (or 800), rabbit anti-goat Alexa Fluor 680 or goat anti-mouse Alexa Fluor 680 (Invitrogen) for $30 \mathrm{~min}$ at room temperature. After washes with PBST, membranes were scanned using the Odyssey Infrared Imaging System (LI-COR Biosciences).

Photoreceptor ultrastructure. Eyes were enucleated and fixed in freshly made $2 \%$ paraformaldehyde, $2.5 \%$ glutaraldehyde, $0.1 \mathrm{M}$ cacodylate buffer, $\mathrm{pH}$ 7.5, for $30 \mathrm{~min}$ before removal of cornea and lens. Enucleated eyes were additionally fixed as mentioned above for $48 \mathrm{~h}$ at room temperature under rotation (nutator). Subsequent dissection, embedding, and transmission electron microscopy were performed as described previously (Goldberg et al., 2007).

Rod OS (ROS) membrane isolation. The isolation of ROS membranes was performed using previously described protocols with modifications (Nickell et al., 2007; Rakshit et al., 2015). ROS membranes were prepared using 20 murine retinae obtained from adult wild-type animals. Briefly, the retinal tissue suspended in $300 \mu \mathrm{l}$ of $8 \%$ (v/v) OptiPrep (SigmaAldrich) in Ringer's buffer (10 mM HEPES, $130 \mathrm{~mm} \mathrm{NaCl}$, $3.6 \mathrm{~mm} \mathrm{KCl}$, $2.4 \mathrm{mM} \mathrm{MgCl}_{2}, 1.2 \mathrm{mM} \mathrm{CaCl}_{2}$, and $0.02 \mathrm{~mm}$ EDTA, $\mathrm{pH}$ 7.4), was vortexed at maximum speed, followed by centrifugation at $250 \times g$ for $1 \mathrm{~min}$. The supernatant was collected. The pellet was resuspended in $300 \mu \mathrm{l}$ of solution containing $8 \%$ OptiPrep in Ringer's buffer. The vortexing and centrifugation steps were repeated as described above for five times. The pooled supernatant samples were layered on a $10-30 \%(\mathrm{v} / \mathrm{v})$ continuous gradient of OptiPrep in $12 \mathrm{ml}$ of Ringer's buffer The gradient was centrifuged for $50 \mathrm{~min}$ at $26,500 \times \mathrm{g}$ at $4^{\circ} \mathrm{C}$ using a Beckman ultracentrifuge (Optima LE-80K; SW-41Ti). Intact ROS membranes were found at twothirds away from the top. The ROS membrane band was recovered by aspiration using a Pasteur pipette and diluted with threefold Ringer's buffer. The resulting suspension was centrifuged for $3 \mathrm{~min}$ at $650 \times \mathrm{g}$. To retrieve ROS membranes, the supernatant was collected and placed in a $1.5 \mathrm{ml}$ ultracentrifuge tube (Beckman $9.5 \times 38 \mathrm{~mm}$ ) and centrifuged for $30 \mathrm{~min}$ at $26,500 \times \mathrm{g}$ using a table top Beckman ultracentrifuge (Optima TLX; rotor-TLA55). The resulting pellet contained the isolated ROS membranes.

Experimental design and statistical analysis. All quantitative analysis was performed on age-matched Arl13b littermate wild-type controls and knock-out animals. For immunohistochemical analysis, at least $4 \mathrm{sec}$ tions were imaged per sample and data were derived from at minimum $n$ $>3$ independent experiments. Statistical analyses were performed using GraphPad Prism software version 7.0. Data are presented as mean \pm SEM. Unpaired Student's $t$ tests were conducted to compare measured values between control and mutant samples. Scotopic and photopic ERG responses were analyzed with two-way ANOVA and then applied Tukey post hoc test for comparison of means between groups with a $p$-value $<0.05$. For cilia measurements, $80-100$ cilia were measured for each animal $(n=3)$ and data were visualized with the ggplot2 package in $\mathrm{R}$ version 3.3.2. Image and densitometry analysis were performed using ImageJ-FIJI 1.50i along with the Bio-Formats plugin. Sex differences were assessed for each outcome measure with no significant change observed.

\section{Results}

\section{ARL13B is present in the photoreceptor OSs}

ARL13B is highly enriched within primary cilia and has been used extensively as a marker in cilia studies (Caspary et al., 2007; Hua and Ferland, 2017). To determine the localization of ARL13B in photoreceptor cells, we performed immunohistochemistry using different commercially available antibodies (Fig. $1 A$ and data not shown). We used antibodies against peripherin-2 (PRPH2) and sodium-potassium ATPase subunit $\beta 2$ (ATP1 $\beta 2$ ) to mark the photoreceptor outer and IS, respectively (Fig. $1 A$, top and bottom). ARL13B was concentrated at the proximal end of the photoreceptor OSs (Fig. 1A). To independently confirm the presence of ARL13B in the OSs, we isolated photoreceptor membrane from adult wild-type retinas. To validate our membrane preparation, we probed for the presence of established markers of IS and OS proteins (Fig. 1B) (Nickell et al., 2007; Skiba et al., 2013; Rakshit et al., 2015). As expected, photoreceptor IS proteins were absent in the isolated ROS membrane fractions (i.e., AIPL1 = aryl hydrocarbon receptor interacting protein like 1; Cyt $\mathrm{C}=$ cytochrome C). Similarly, Go $\alpha$, a protein localized to ON bipolar cells that are downstream of photoreceptors, was not present in the membrane fraction (Vardi, 1998). Interestingly, we found ARL13B in both the total and membrane fractions. Additionally, we found enrichment of photoreceptor OS membrane-resident proteins in the ROS membrane fraction compared with the total fraction (i.e., rhodopsin; $\mathrm{G} \alpha \mathrm{T} 1=$ transducin- $\alpha$ subunit; $\mathrm{PRCD}=$ progressive rod-cone degeneration protein), further validating our membrane preparation. Together, our results show ARL13B is predominantly localized to the photoreceptor OSs. Furthermore, our results suggest ARL13B is associated with photoreceptor ROS membranes. 
A
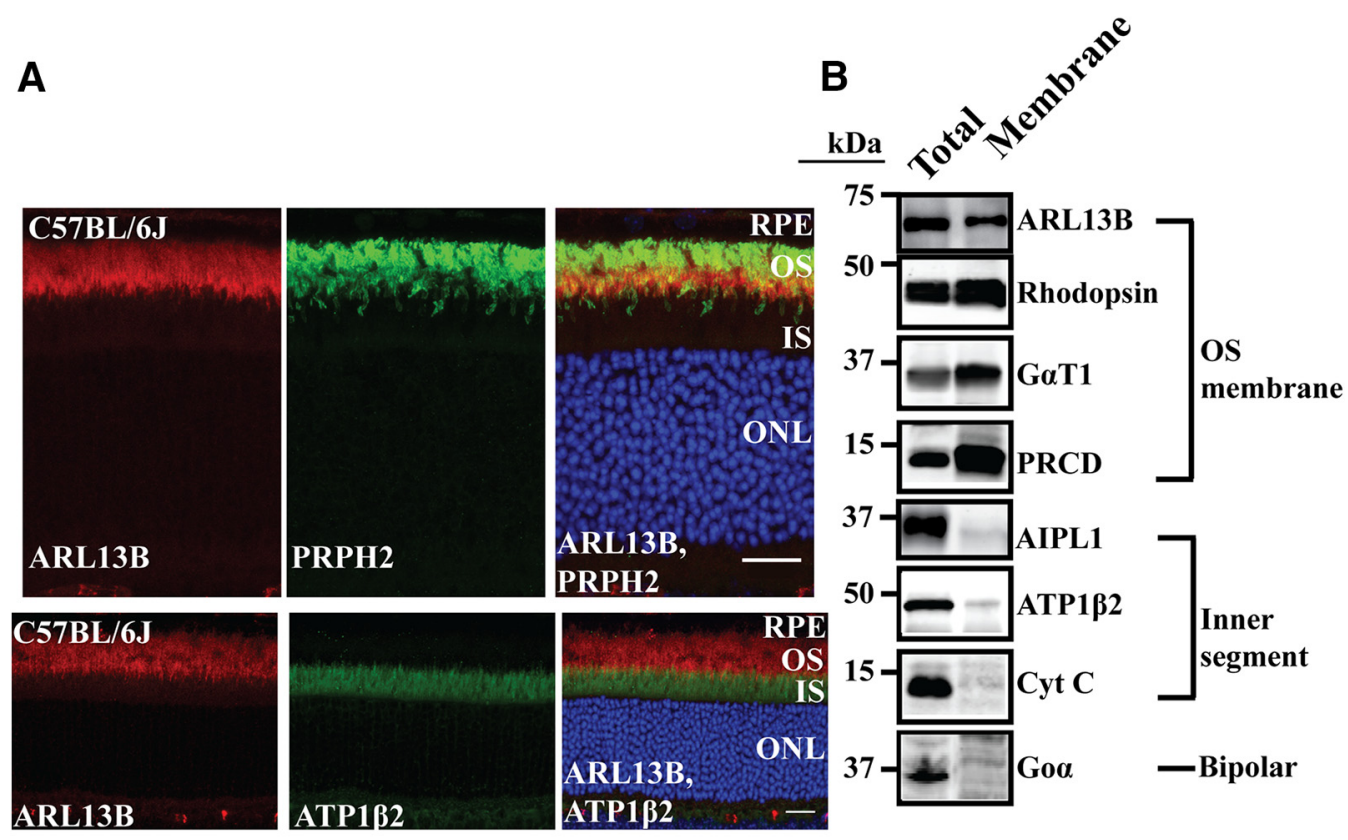

C
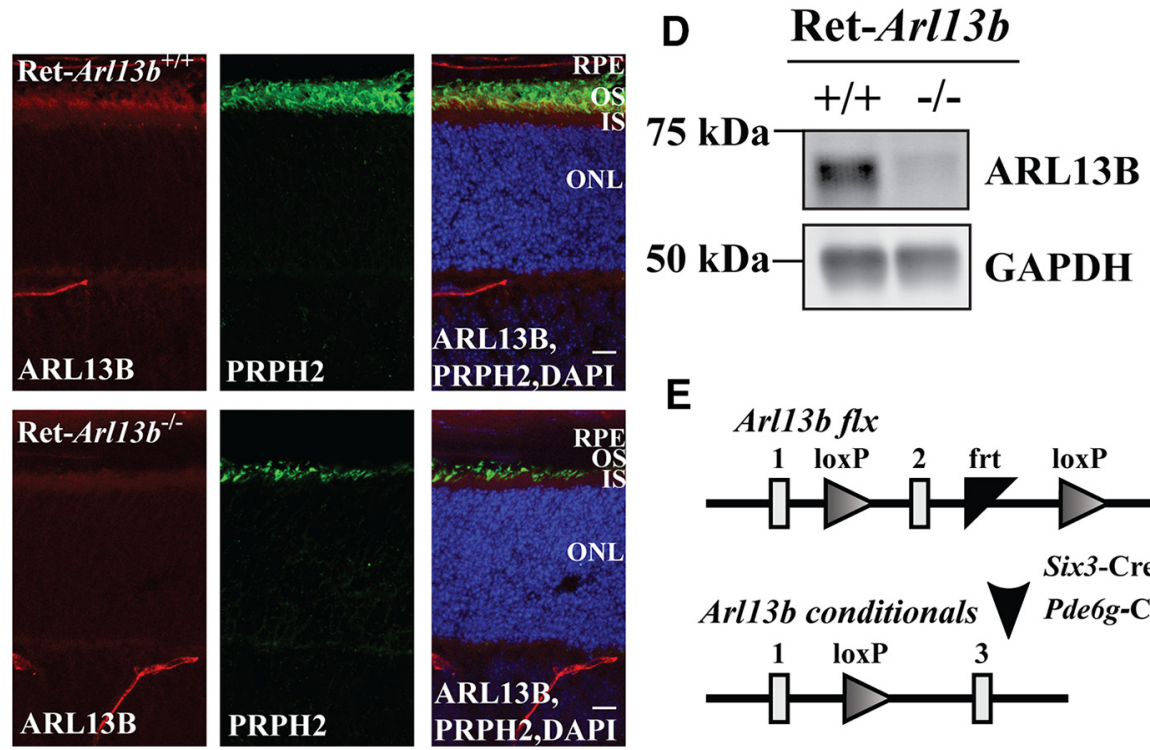

E
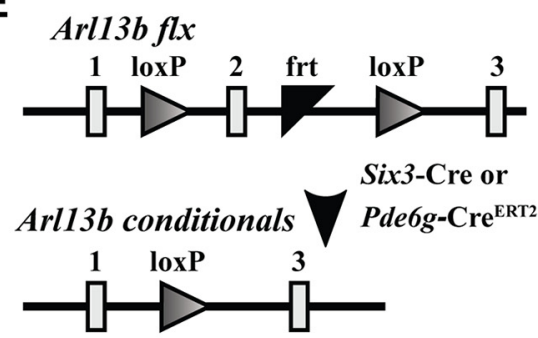

Figure 1. Validation of animal model and localization of ARL13B in murine retina. $A, B$, Immunolocalization of ARL13B in the murine retina. $A$, Top, Retinal cross-sections of P30 wild-type animals (C57BL/6J) stained against ARL13B (red) and PRPH2, an 0S marker, stained in green. Bottom, Retinal cross-sections of P30 wild-type animals (C57BL/6J) stained against ARL13B (red) and ATP1 $\beta 2$, an IS marker, stained in green. Scale bar, $20 \mu \mathrm{m} . \boldsymbol{B}$, Immunoblot showing subcellular localization of ARL13B in photoreceptors. ROS membrane fractions were isolated as described in Materials and Methods. Total fraction represents the retinal lysate that was the starting material for ROS isolation. The proteins found in specific photoreceptor compartments were used for validation of the isolated ROS, including: OS proteins (rhodopsin, G $\alpha \mathrm{T} 1$ : rod transducin- $\alpha$ subunit), IS proteins (AIPL1: Aryl Hydrocarbon Receptor Interacting Protein Like-1, Cyt C: cytochrome c and bipolar cell protein, Go $\alpha$. C $-\boldsymbol{E}$, Validation of Ret-Arl136 $b^{-1-}$ animal models by immunofluorescence and immunoblot analysis. C, Retinal cross-sections probed for ARL13B from Ret-ARL13B ${ }^{-1-}$ (Six3-Cre

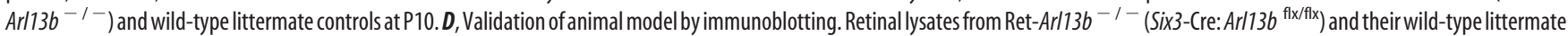
controls at P10 probed against ARL13B and GAPDH that served as a loading control $(n=3)$. $\boldsymbol{E}$, Scheme depicting the generation of conditional Arl13b animal models. LoxP flanks exon 2 of Arl13b. Following Cre expression from either Six 3 or Pde6g promoter, exon 2 of Arl13b is removed in a tissue- and/or cell-specific manner.

Generation of Arl13b animal models

To determine the role of ARL13B in the retina, we generated a pan-retina Arl13b knock-out using Cre-loxP recombination technology. Arl13b floxed animals contained loxP sites flanking exon 2 (Fig. 1C) (Su et al., 2012). Arl13b-floxed animals were crossed with a Cre recombinase driver line under the retina and forebrain-specific promoter Six 3 , with excision taking place at embryonic day 9.5 (Furuta et al., 2000). We next verified the validity of our animal model by probing for ARL13B using immunohistochemistry and immunoblotting
(Fig. 1C,D). As expected, ARL13B was absent in Six3-Cre: Arl13b flx/flx (Ret-Arl13b ${ }^{-1-}$ ) animals compared with their littermate controls, Arl13b ${ }^{\mathrm{fl} / \mathrm{flx}}$ or Six3-Cre: Arl13b ${ }^{\mathrm{flx} /+}$ (Ret$A r l 13 b^{+/+}$) (Fig. 1C,D). In agreement with previous findings, we found that ARL13B exhibits an anomalous SDS-PAGE mobility, running at $\sim 60 \mathrm{kDa}$ rather than the $48 \mathrm{kDa}$ molecular weight predicted by its amino acid sequence (Caspary et al., 2007; Ivanova et al., 2017). At postnatal day 10 (P10), the majority (>90\%) of ARL13B protein was lost in RetArl13b ${ }^{-1-}$ mutants (Fig. 1D). 
A

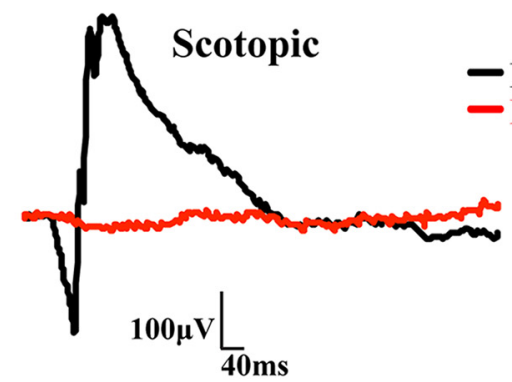

Photopic

B

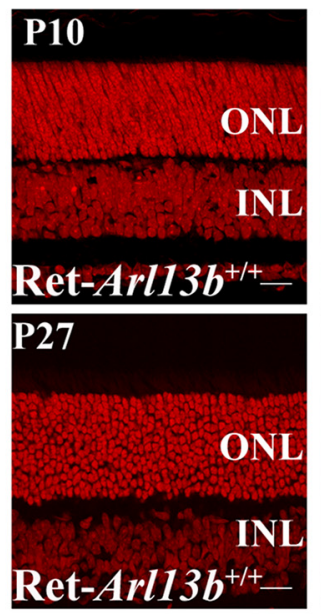

D

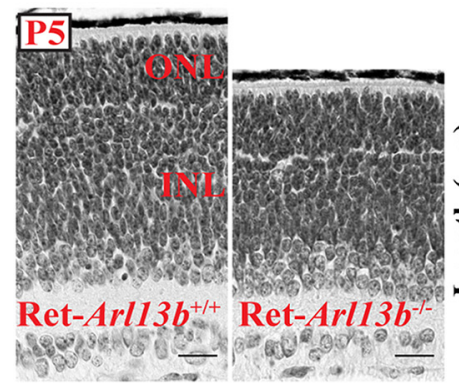

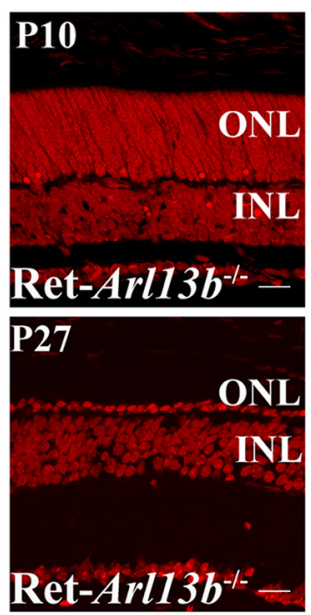

E

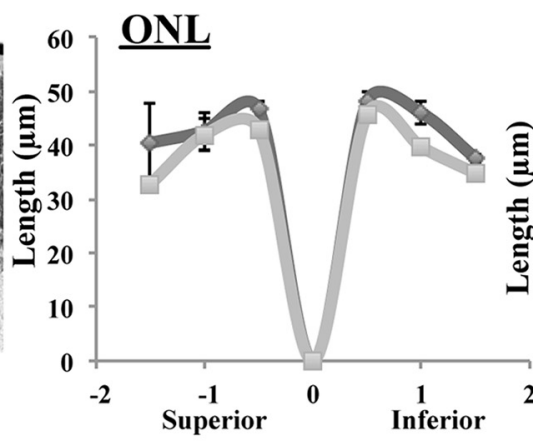

$\leadsto$ Ret- $A r l 13 b^{+/+}$

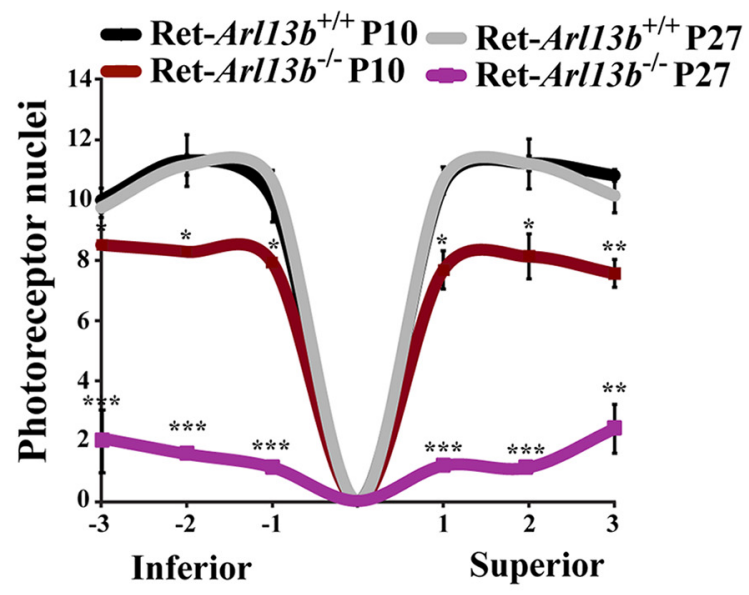

F
$10 \mu \mathrm{V} \bigsqcup_{40 \mathrm{~ms}}$

C

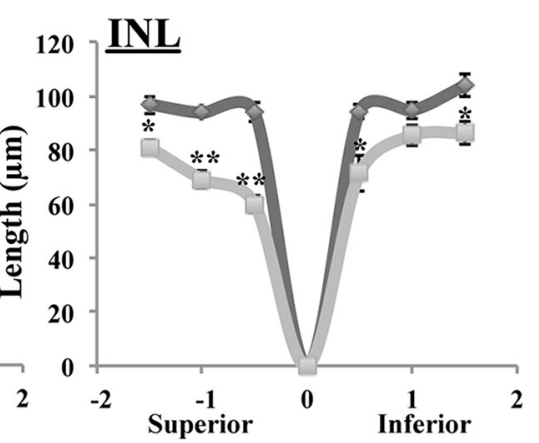

Figure 2. Reduced retinal thickness and rapid photoreceptor degeneration in ARL13B-null retinas. $A$, Representative scotopic $\left(-0.8 \log \mathrm{cd}^{*} \mathrm{~s} / \mathrm{m}^{2}\right)$ and photopic $\left(0.7 \mathrm{log} \mathrm{cd}^{*} \mathrm{~s} / \mathrm{m}^{2}\right)$ ERGs of Ret-Arl13b $b^{-1-}$ (red) and littermate control (black) at P15. B, Retinal cross-sections stained with propidium iodide at P10 and P27. Scale bar, $20 \mu$ m. C, Quantification of the 0NL thickness (cell nuclei) at different sites along the retina from the inferior to superior regions between Ret-Arl13b- $I-$ and wild-type littermate controls at P10 and P27. Data are represented as mean $\pm S E M$ $\left(n=3\right.$, unpaired two-tailed $t$ test; $\left.{ }^{* * *} p \leq 0.0001 ;{ }^{* *} p \leq 0.001 ;{ }^{*} p \leq 0.01\right)$. D, Light microscopy of hematoxylin and eosin (H\&E)-stained cross-sections of Ret-Arl13b ${ }^{-} /$- mutant and wild-type littermate control at P5. $\boldsymbol{E}, \boldsymbol{F}$, Graphs depicting length measurements of the developing ONL $(\boldsymbol{E})$ and inner nuclear layer (INL) $(\boldsymbol{F})$ from Ret-Arl13b ${ }^{-/-}$mutants and their wild-type littermate controls $\left({ }^{* *} p=0.001,{ }^{*} p=0.01 ; n=3\right)$.

ARL13B is essential for postnatal retinal development To examine the impact of ARL13B deletion on photoreceptor function, we performed ERG tests. ERG measures the electric potential generated by the retinal cells in response to a light stimulus. The activity by photoreceptors and depolarization of bipolar cells results in the generation of "a-waves" and "b-waves," respectively (Pinto et al., 2007; Quinteros et al., 2016). At P15, after mice open their eyes, in Ret-Arl13b ${ }^{-1-}$ animals we observed a severe loss of rod (scotopic) and cone (photopic) photoreceptor function (Fig. 2A).
The observed loss of photoreceptor function could be due to photoreceptor cell death. Therefore, we counted photoreceptor nuclei at $\mathrm{P} 10$ and $\mathrm{P} 27$ (Fig. $2 \mathrm{~B}, \mathrm{C}$ ). At $\mathrm{P} 10$, we observed a reduction in photoreceptor nuclei in retina lacking ARL13B (Fig. 2C; Ret-Arl13b $b^{+/+}=10.6 \pm 0.32$ vs Ret-Arl13b $b^{-1-}=6.8 \pm 0.21$ rows of nuclei, $P=0.0006 ; n=3$ ). By P27, we detected rapid photoreceptor degeneration with extensive loss occurring in the central retina (Fig. 2C; Ret-Arl13b $b^{+/+}=10.9 \pm 0.18$ vs RetArl13b $b^{-1-}=1.24 \pm 0.12$ rows of nuclei, $P=0.0001 ; n=3$ ) compared with the peripheral edges of the retina (Fig. $2 C$; Ret- 
A
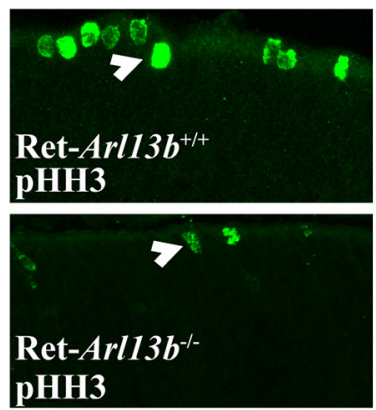

C
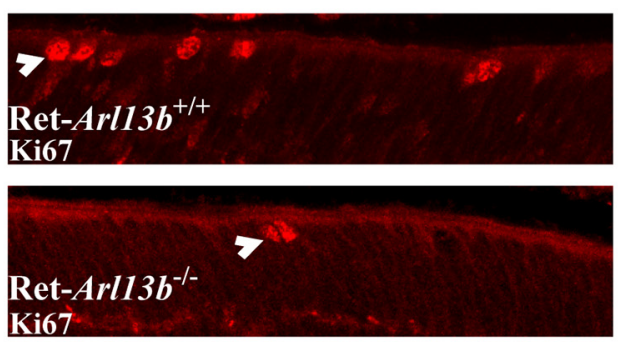

D
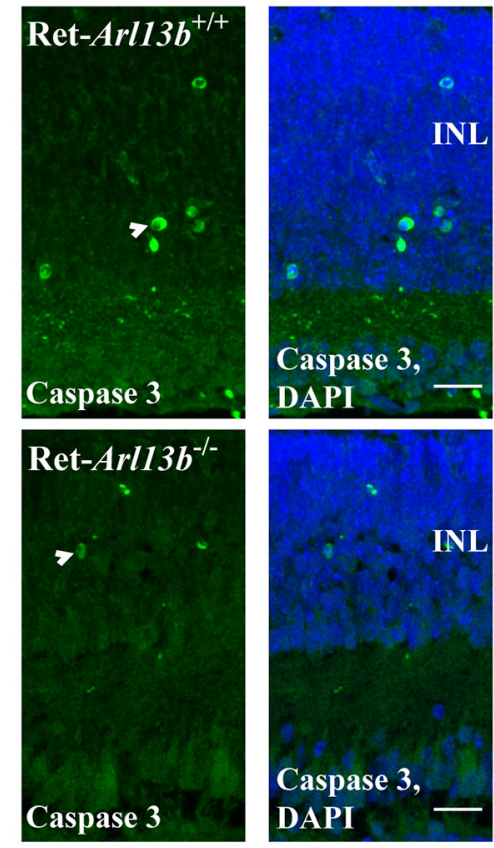

E

F

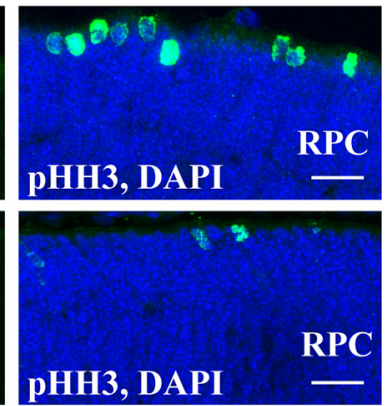

B

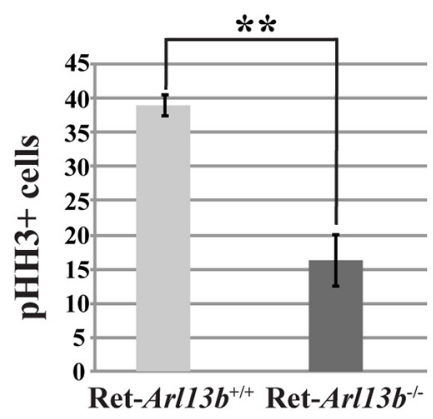

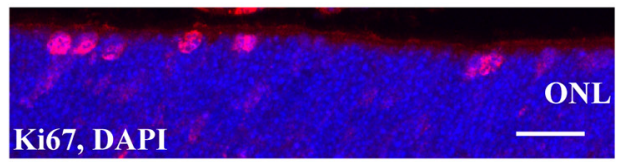

K67, DAPI

$* *$
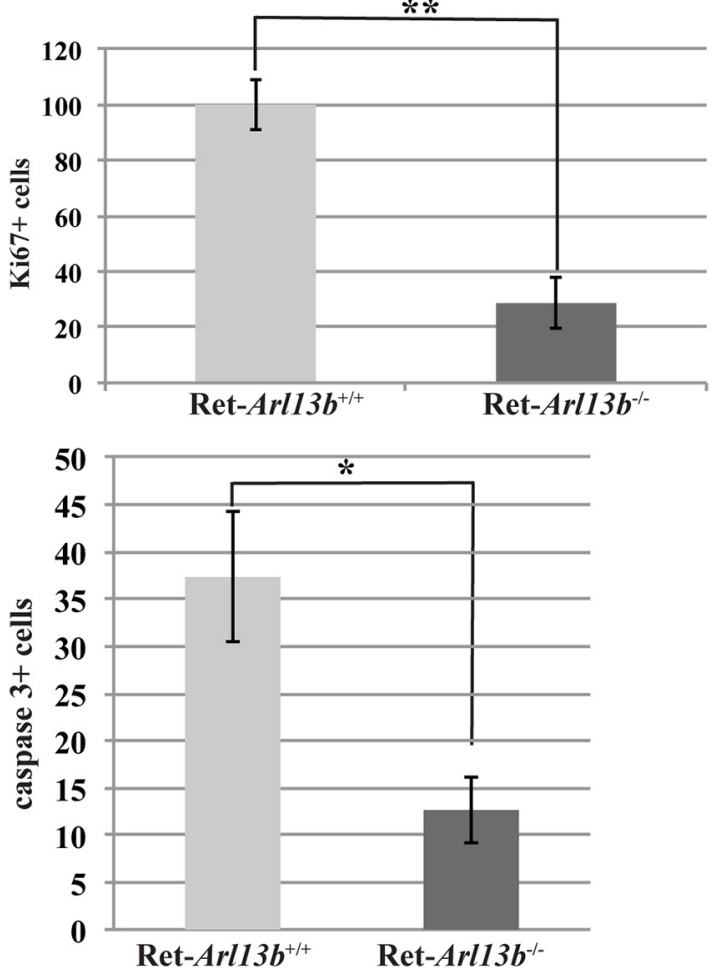

Figure 3. Defective retinal development in the absence of ARL13B. A, Retinal cross-sections of Ret-Ar/13b ${ }^{-1-}$ and wild-type littermate controls stained against the proliferation marker pHH3 (green, marked by arrowheads) at P5. Scale bar, $20 \mu \mathrm{m}$. B, Quantifications of pHH3-positive cells across the retina from Ret-Arl13b-null animals and littermate controls at P5. Data are represented as mean \pm SEM $\left(n=3\right.$, Student's $t$ test; $\left.{ }^{* *} p=0.005\right)$. C, Retinal cross-sections from Ret-Arl13b $b^{-1-}$ and littermate controls stained with the proliferation marker Ki- 67 at P5 (red, marked by

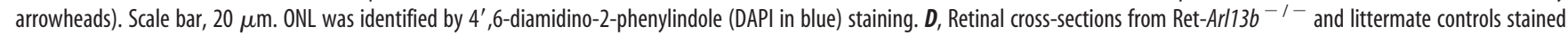
with apoptotic marker caspase-3 at P5 (Green, marked by arrowheads). Scale bar, $20 \mu \mathrm{m}$. INL, Inner nuclear layer identified by DAPI staining. $\boldsymbol{E}$, Quantification of Ki-67-positive cells identified in $\boldsymbol{C}$. Data are represented as mean $\pm \operatorname{SEM}\left(n=3\right.$, unpaired two-tailed $t$ test; $\left.{ }^{* *} p=0.005\right)$. $\boldsymbol{F}$, Quantification of caspase-3-positive cells identified in $\boldsymbol{D}$. Data are represented as mean \pm SEM ( $n=3$, unpaired two-tailed $t$ test; ${ }^{*} p=0.05$ ).

Arl13b $b^{+1+}=9.9 \pm 0.16$ vs Ret-Arl13b $b^{-1-}=2.2 \pm 0.13$ rows of nuclei, $P=0.0001 ; n=3)$. The retinal thickness was also reduced in the developing retina at $\mathrm{P} 5$ (Fig. 2D-F).

Due to the early loss of photoreceptor nuclei in RetArl13b $b^{-1-}$ mutants and the role for ARL13B in proliferation, we further investigated whether the loss of ARL13B would affect retinal proliferation at early stages of development (Fig. 3) (Bay et al., 2018). We stained cross-sections of Ret-Arl13b ${ }^{-1-}$ and littermate wild-type controls at $\mathrm{P} 5$ for phospho-histone $\mathrm{H} 3$ ( $\mathrm{pHH} 3$ ), a late $G_{2}$ to $M$ phase marker that primarily labels mitotic progeni- 
tors and Ki-67, a marker found to primarily label late $G_{1}$ to $M$ phase proliferating cells (Fig. 3 A, C) (Hendzel et al., 1997; Mongan et al., 2011; Suga et al., 2014). As expected, pHH3-positive cells were detected around the outer edges of the retina in both Ret-Arl13b $b^{-1-}$ and wild-type littermate controls at P5 (Fig. 3A) (Mongan et al., 2011). Interestingly, the number of pHH3positive cells was decreased by $58 \%$ in retinas lacking ARL13B (Fig. $3 B$; Ret-Arl13b $b^{+/+}=39 \pm 1.5$ vs Ret-Arl13b $b^{-1-}=16.3 \pm$ $3.7, p=0.005 ; n=3)$. We observed a similar reduction in proliferation (71.4\%) with Ki-67 staining in Ret-Arl13b $b^{-1-}$ animals compared with wild-type littermate controls (Fig. 3E; RetArl13b $b^{+/+}=100 \pm 8.9$ vs Ret-Arl13b $b^{-1-}=28.3 \pm 9.7, p=$ $0.005 ; n=3)$. When we tested for apoptosis using activated caspase-3, we also observed reduced staining in the retina lacking ARL13B (Fig. 3D,F; Ret-Arl13b $b^{+/+}=37.3 \pm 6.8$ vs RetArl13b $\left.b^{-1-}=13.0 \pm 3.4, p=0.03 ; n=3\right)$. These results indicate that the initial development and function of photoreceptor cells is severely affected in the absence of ARL13B.

\section{Robust reduction of photoreceptor OS-resident proteins in the absence of ARL13B}

Based on previous studies implicating ARL13B as the GEF for ARL3 and the known role for ARL3 in trafficking of prenylated PDE6, we investigated whether loss of ARL13B perturbed the movement of PDE6 into the OS (Gotthardt et al., 2015; Zhang et al., 2016). We probed for PDE6 by immunohistochemistry using retinal cross-sections from Ret-Arl13b $b^{-1-}$ and their wild-type littermate controls at P10 (Fig. $4 A, B$ ). PDE6 $\beta$ was found properly localized to the OS (Fig. $4 A$ ), but at reduced levels in retinas lacking ARL13B, which were later confirmed by immunoblot (73\% reduction for PDE6 $\beta, p=0.001, n=3$; Fig. $4 D, E)$. The staining for PDE6 was not uniform; in some areas of the retina, PDE6 staining was completely absent in Ret-Arl13b $b^{-1-}$ animals (Fig. 4B). Although the majority of rhodopsin protein was found targeted to the OS, we detected mislocalized rhodopsin in the photoreceptor ONL in Ret-Arl13b $b^{-1-}$ animals (Fig. 4A,B). Additionally, non-prenylated $\mathrm{PRPH} 2$ was found properly targeted to the photoreceptor OS in retinas lacking ARL13B at P10 (Fig. $4 C$ ). In agreement with our results from immunohistochemistry, we observed an overall reduction of photoreceptor OS-resident proteins in the absence of ARL13B at P10 by immunoblotting (Fig. $4 D, E$ ). Specifically, we found $70 \%$ and $60 \%$ reduction of Transducin (G $\alpha \mathrm{T} 1)$ and PRPH2, respectively, in Ret-Arl13b $b^{-1-}$ animals at P10 (G $\alpha \mathrm{T} 1, p=0.03$; PRPH2, $p=0.004, n=3$; Fig. $4 D, E)$. Last, similar to PDE6, we found a trend in decreased relative protein levels of the prenylated protein rhodopsin kinase-1 (GRK1) in Ret-Arl13b ${ }^{-1-}$ at P10 (Fig. 4D,E). In summary, ARL13B deletion led to a reduction in the majority of OS-resident proteins.

\section{ARL13B is required for photoreceptor OS biogenesis}

Staining for several OS-resident proteins including PRPH2 in retinas lacking ARL13B revealed shorter OSs, suggesting a defect in OS structure (Fig. 4). Therefore, we performed transmission electron microscopy (TEM) to conduct ultrastructural analyses of the retinas from Ret-Arl13b $b^{-1-}$ and littermate controls (Fig. 5). At P10, electron micrographs revealed OSs that displayed well ordered stacked discs in wild-type littermate controls (Fig. $5 A, C)$. In contrast, TEM analysis of P10 ARL13B-null retinas revealed a complete absence of recognizable OSs (Fig. $5 B$ ). We observed a few "OS rudiments" in the retinas lacking ARL13B; however, they were highly vesiculated and lacked the characteristic stacked discs (Fig. 5D-F). Interestingly, we observed the presence of extracellular vesicles (ectosomes) with uniform diameter in the subretinal space of Ret-Arl13B ${ }^{-1-}$ mutants at P10 (202 $\pm 54 \mathrm{~nm}$; mean $\pm \mathrm{SD}$; Fig. $5 G, H$, red arrowheads). These results illustrate a crucial role for ARL13B in the elaboration of photoreceptor OSs and stacked disc membranes.

\section{Basal body positioning and ciliary extension are disrupted in ARL13B-null retinas}

Loss of ARL13B leads to reduced numbers of primary cilia and dysregulation of ciliary length (i.e., shorter cilia) (Caspary et al., 2007; Larkins et al., 2011). To evaluate the effects of ARL13B deletion on photoreceptor cilia, we performed immunohistochemistry in lightly fixed retinal cross-sections using various ciliary markers at P10, a common approach used to characterize photoreceptor cilia length (Omori et al., 2010; Sedmak and Wolfrum, 2010) (Fig. 6). At P10, rootletin staining (Fig. 6A, left; rootletin in green) revealed shorter ciliary rootlets in RetArl $13 b^{-1-}$ animals compared with littermate controls, suggesting shorter photoreceptor ISs, which was confirmed through ultrastructural analysis. The axonemal marker male germ cellassociated kinase (MAK) was expressed in a punctate fashion and was mislocalized to the IS in Ret-Arl13b- $b^{-1-}$ retinas (Fig. 6A; MAK in cyan). To independently verify these defects in the axoneme, we assessed the localization of Retinitis Pigmentosa-1 (RP1), a microtubule-associated protein (MAP) primarily found in the photoreceptor axoneme (Liu et al., 2004). We also costained with acetylated tubulin, a hallmark of long-lived microtubules primarily found along the photoreceptor connecting cilia/transition zone and the base of the photoreceptor axoneme (Fig. 6B) (Arikawa and Williams, 1993; Omori et al., 2010; Portran et al., 2017). As expected, RP1 was present in photoreceptor axonemes in wild-type littermate controls. However, in photoreceptors lacking ARL13B, RP1 was found in a punctate pattern and was mislocalized to the IS. Interestingly, acetylated tubulin was mislocalized to the outer nuclear layer (ONL) of RetArl13b $b^{-1-}$ animals (Fig. 6B, yellow arrowheads). Ultrastructural analysis (at P10) revealed that basal bodies in the knock-out retina were displaced and often found within the ISs adjacent to the outer limiting membrane (Fig. $6 C, E$, Ret-Arl13b $b^{+/+}=12 \%$ vs Ret-Arl13b $b^{-1-}=47 \%$ displaced BBs; $\left.n=3, p=0.0002\right)$. To corroborate the observed defects in basal body positioning, we probed for centrin in Ret-Arl13b $b^{-1-}$ and littermate controls (Fig. 6D). Centrin is commonly used basal body marker in photoreceptors, where it associates with centrioles and, to a lesser extent, the inner face of the microtubule doublets of the connecting cilium (Wolfrum et al., 2002). We observed centrin staining adjacent to the top layer of photoreceptor nuclei as well as closer to the basal side of the IS in retinas lacking ARL13B (Fig. 6D, white arrowheads). Altogether, our results suggest ARL13B plays a role in axonemal/ciliary extension, potentially by an effect on photoreceptor basal body positioning.

\section{ARL13B is essential for rod photoreceptor maintenance}

Our studies using embryonic deletion of ARL13B in the murine retina establish the essential need for ARL13B in the early development of photoreceptor cilia and OS morphogenesis in mice. However, rapid photoreceptor degeneration, disrupted OS elaboration, and the fact that ARL13B was ablated in other retinal cell types prevented us from establishing a direct role for ARL13B in photoreceptors. In addition, we wanted to investigate whether ARL13B's function is restricted to the early phase of photoreceptor development or if it also plays a critical role in the mainte- 

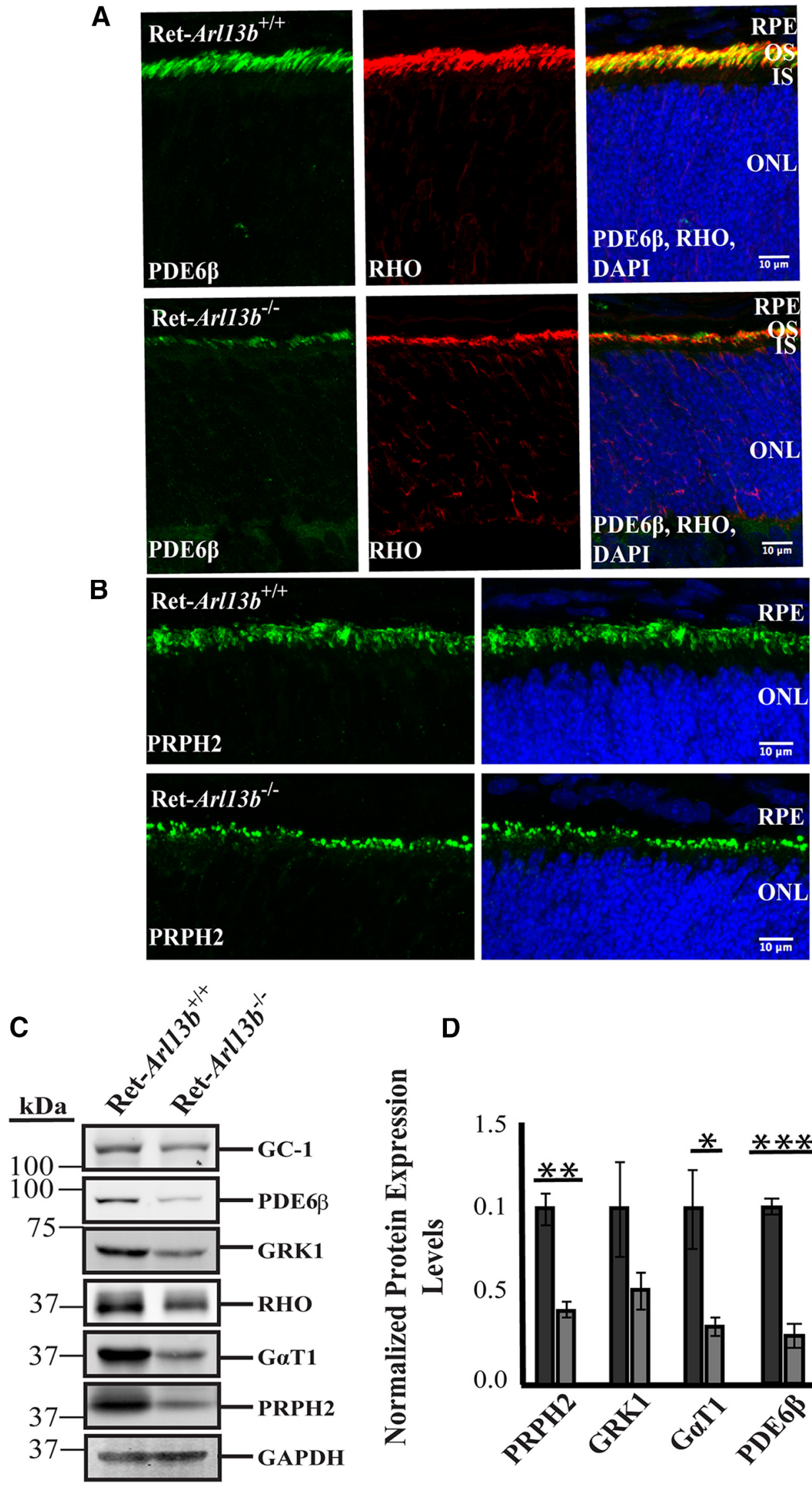

D

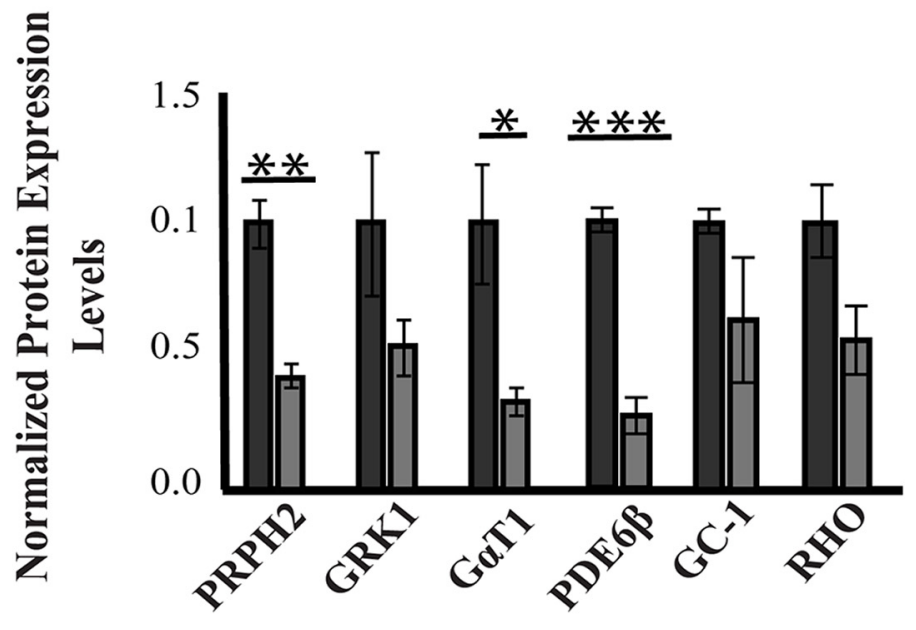

Figure 4. Reduced expression of OS proteins in retinas lacking ARL13B. $A, B$, Retinal cross-sections from P10 Ret-Arl13b $b^{-1}$ - and wild-type littermate controls stained against rhodopsin (red), Phosphodiesterase-6 $\beta$ subunit (PDE6 $\beta$ : green), and DAPI (4',6-diamidino-2-phenylindole). Scale bar, $20 \mu$ m. C, Retinal cross-sections of Ret-Ar136 $b^{-1-}$ and littermate wild-type controls stained against 0S-resident protein PRPH2 (green) at P10. Scale bar, $10 \mu \mathrm{m}$. D, Immunoblot of P10 retinal lysates from indicated genotypes probed for different (Figure legend continues.) 

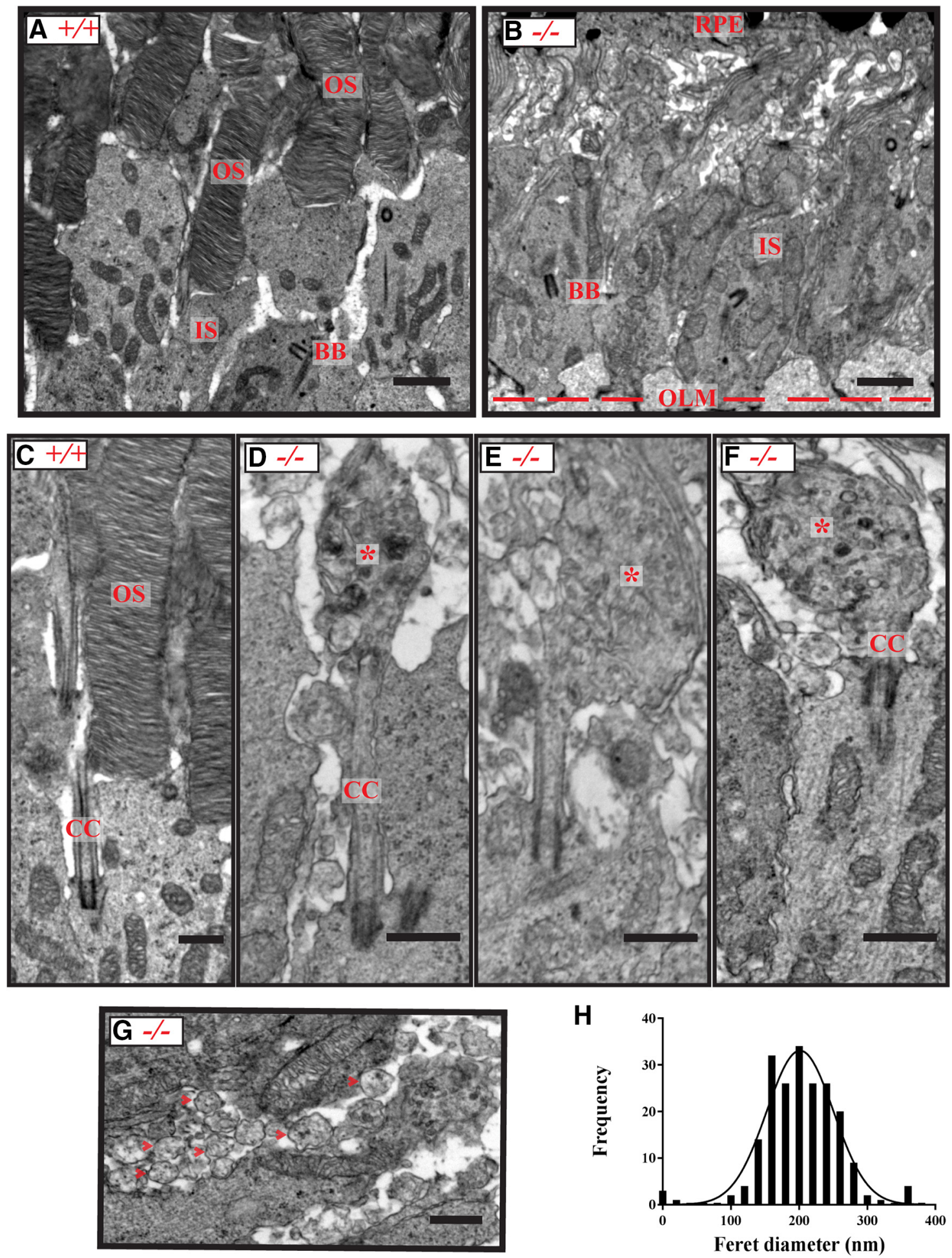

Figure 5. ARL13B is needed for normal development of photoreceptor OSS. $A$, TEM image of the photoreceptor OS-retinal pigment epithelium (OS-RPE) interface from a wild-type littermate control showing properly developing 0 Ss possessing numerous well ordered membranous discs. Scale bar, $500 \mathrm{~nm}$. B, TEM image of the photoreceptor OS-RPE interface from a P10 Ret-Arl13b ${ }^{-1-}$ animal, showing that the IS-0S boundary for photoreceptors is significantly affected compared with littermate controls. Scale bar, $500 \mathrm{~nm}$. C, Left, Wild-type littermate control, showing normal photoreceptor connecting cilia (CC) and OSs compared with a TEM image from an Ret-Arl136 $b^{-1-}(\boldsymbol{D}-\boldsymbol{F})$ retina displaying a vesicle-filled 0 S rudiment (indicated by asterisk). Scale bars, $500 \mathrm{~nm}$. BB, Basal body; 0LM, outer limiting membrane. G, Electron micrograph of P10 Ret-Arl136 $b^{-1-}$ cross-sections, red arrowheads showing the accumulation of extracellular vesicles in the subretinal space. Scale bar, $500 \mathrm{~nm}$. $\boldsymbol{H}$, Gaussian histogram of Feret diameters for extracellular vesicles in Ret-Arl136 $b^{-\prime-}$ retinas ( $n=204$ pooled from three animals).

$\leftarrow$

(Figure legend continued.) $\quad$ OS-resident proteins (GC-1 = guanylate cyclase-1, RHO = rhodopsin, $G \alpha \mathrm{T} 1=$ rod transducin- $\alpha$ ). GAPDH serves as loading control. $E$, Quantification of $0 S$ proteins $(n=3)$, normalized against GAPDH. Data are represented as mean \pm SEM. ${ }^{* * *} p=$ $0.001 ;{ }^{*} p=0.004,{ }^{*} p=0.03$ as determined by Student's $t$ test. nance of fully developed photoreceptors. To address some of these questions, we depleted ARL13B in mature adult murine rod photoreceptor neurons through the use of a tamoxifen-inducible Cre-LoxP system. The Cre-recombinase $\left(\mathrm{Cre}^{\mathrm{ERT} 2}\right)$ is expressed 

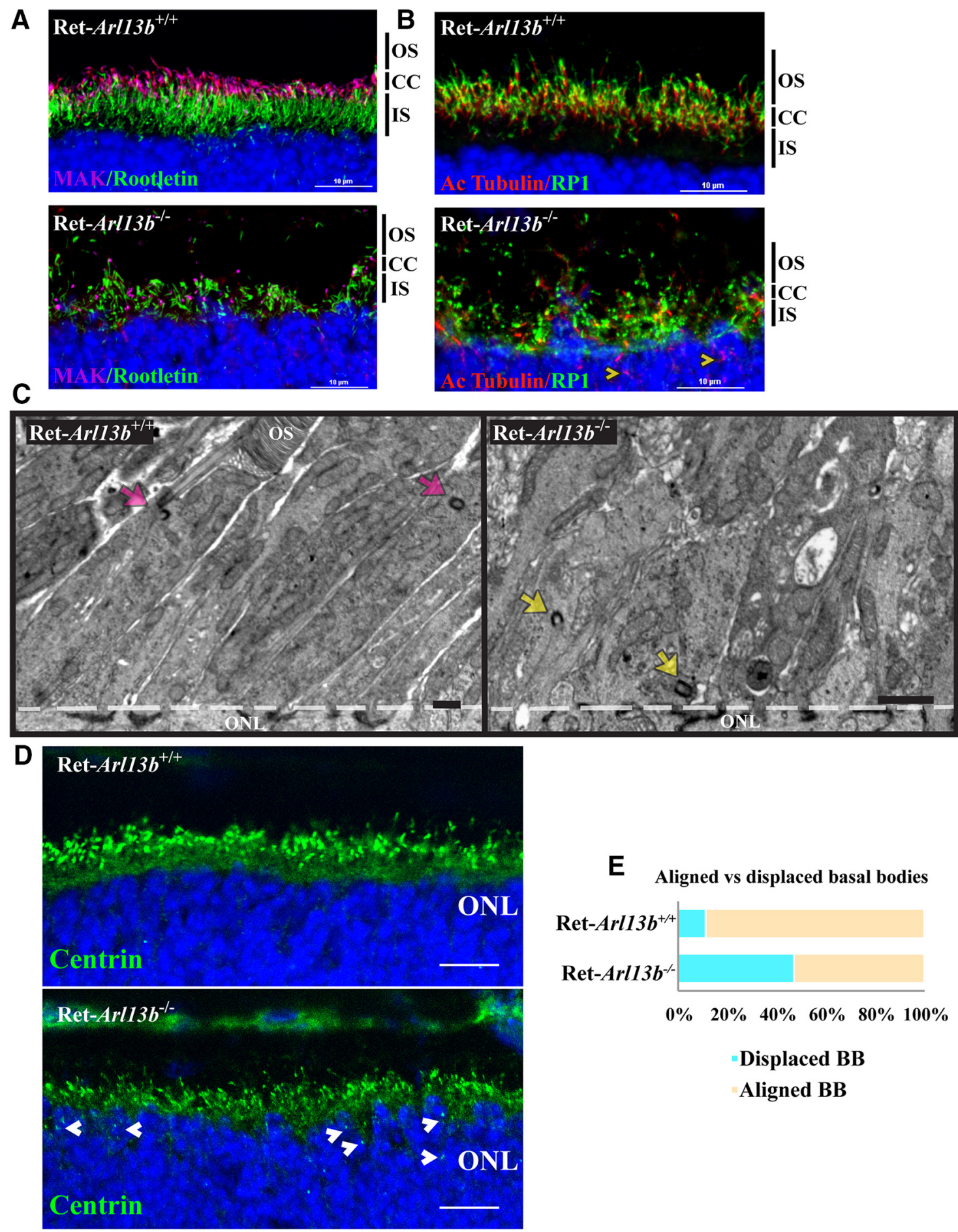

\section{E Aligned vs displaced basal bodies}

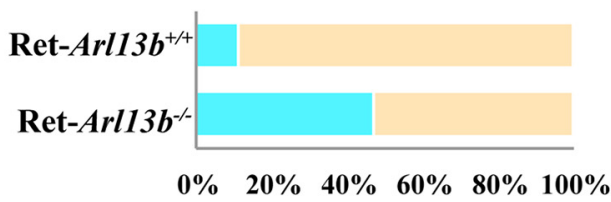

\section{Displaced BB \\ Aligned BB}

Figure 6. Severe ciliary defects in retinas lacking ARL13B. A, Retinal cross-sections of Ret-Ar/136 ${ }^{-1-}$ and wild-type littermate controls stained against axonemal marker MAK (cyan) and IS marker rootletin (green). $\boldsymbol{B}$, Immunofluorescence images of Ret-Arl136 $b^{-1-}$ and littermate controls showing staining against additional axonemal marker RP1 (green) and connecting cilium marker acetylated tubulin (red). Scale bars, $10 \mu \mathrm{m}$. C, Left, TEM images of wild-type littermate controls showing properly docked mother and daughter centrioles (basal body) (cyan arrows). Right, Electron micrographs of P10 Ret-Arl136 $b^{-1-}$ mutants showing displaced solitary basal bodies (yellow arrows). Scale bars, $1 \mu \mathrm{m} . \boldsymbol{D}$, Representative immunofluorescence staining of Centrin (green) in Ret-Arl136 $b^{+/+}$and Ret-Arl13B ${ }^{-1-}$, the latter showing signs of displaced basal bodies (white arrowheads). Scale bar, $10 \mu \mathrm{m}$. Graphs depict the percentage of normal mother and daughter centrioles also known as basal bodies versus the observation of just one solitary centriole in retinas lacking ARL13B at P10 (Ret-Arl136 $b^{+/+}=59$ (solitary centriole)/121 total vs Ret-Arl136 $b^{-I-}=$ 167 (solitary centriole)/237 total; $n=3$, unpaired two-tailed $t$ test, $p=0.0002$ ). $\boldsymbol{E}$, Graphs depicting the percentage of docked basal bodies versus displaced basal bodies in retinas lacking ARL13B at P10 (Ret-Arl136 $b^{+/+}=14$ (displaced BBs)/121 total vs Ret-Arl136 $b^{-1-}=111$ (displaced BBs)/237 total; $n=3$, unpaired two-tailed $t$ test, $p=0.0002$ ).

under the rod-specific phosphodiesterase-6 gamma subunit (Pde6g) promoter (Koch et al., 2015).We crossed this line with Arl13b floxed animals to generate a rod-specific inducible animal model $\left(P d e 6 g-C r e^{\mathrm{ERT} 2}-A r l 13 b^{\mathrm{flx} / \mathrm{flx}}\right)$. ARL13B deletion in rod photoreceptors was induced by intraperitoneal injections of tamoxifen at concentrations of $100 \mu \mathrm{g} / \mathrm{g}$ body weight for 3 consecutive days ( 1 injection/d) at P60. We performed functional tests (ERGs) 2 weeks after injections and observed no significant 


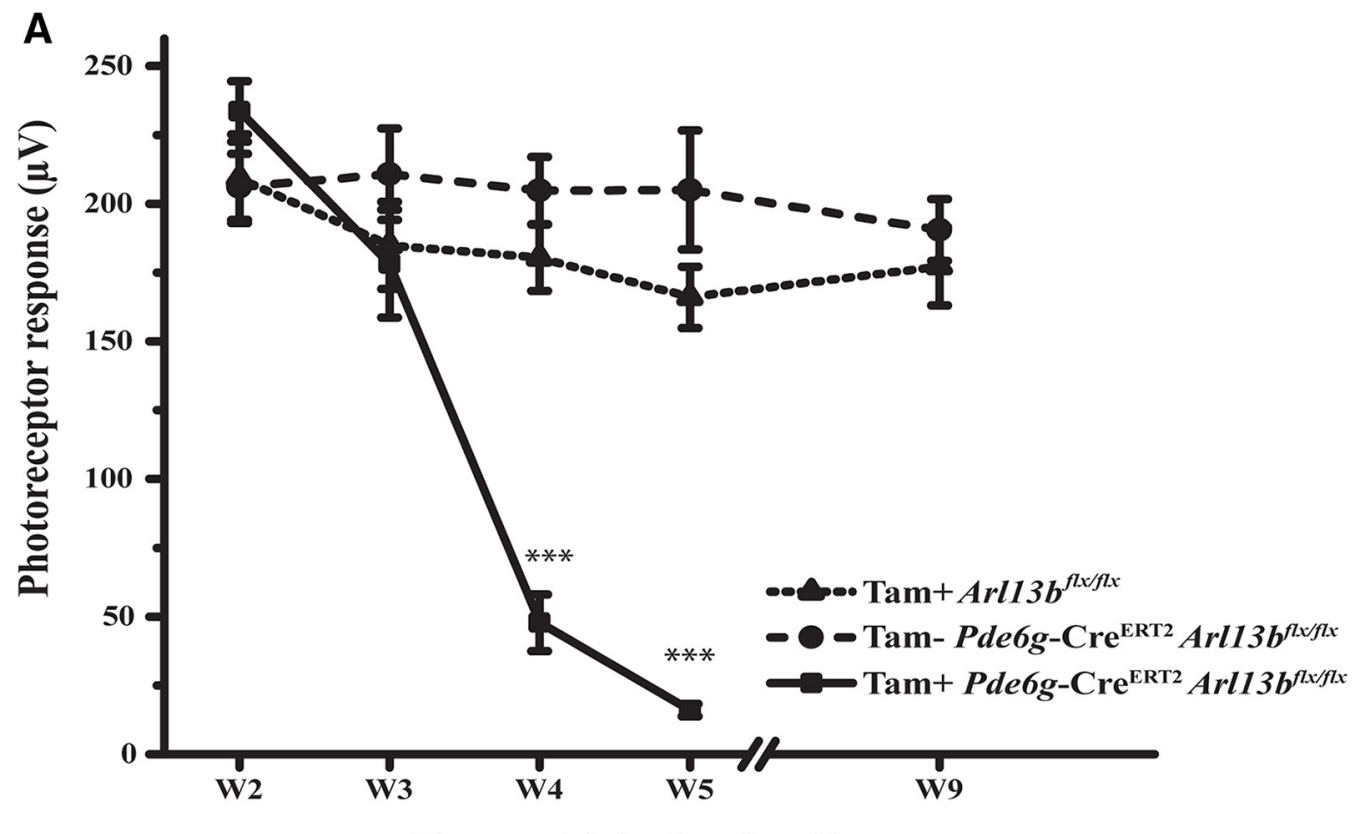

Time post injection (week)

B
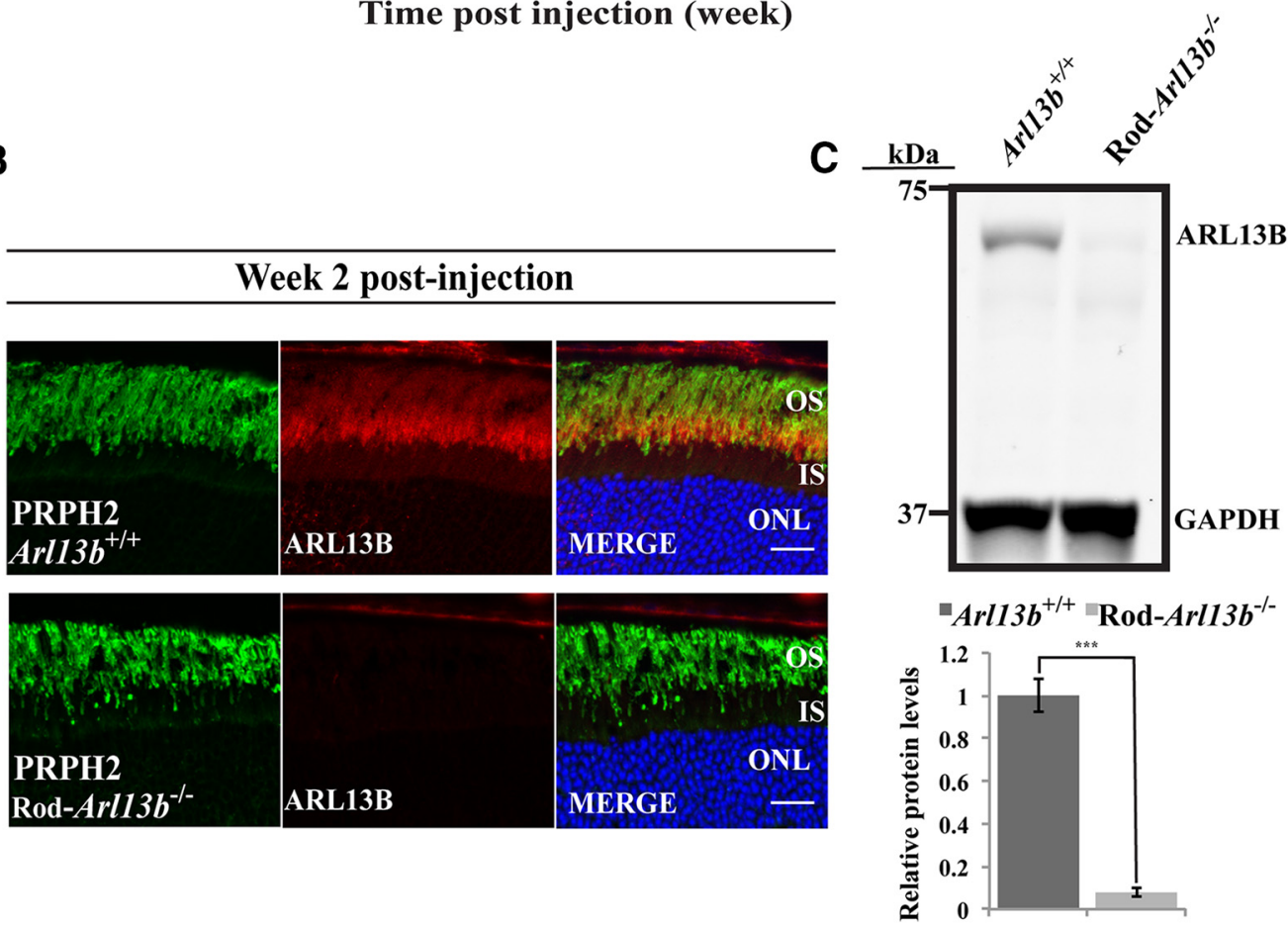

Figure 7. Progressive decline of rod photoreceptor function after removal of ARL13B in mature rod photoreceptors. $A$, Loss of rod photoreceptor response measured by " $a$ " wave response plotted against time in weeks after tamoxifen injections (Tam ${ }^{+}=$tamoxifen injected). Data are represented as mean \pm SEM $\left(n=6\right.$, two-way ANOVA; $\left.{ }^{* * *} p=0.005\right)$. $\boldsymbol{B}$, Immunohistochemistry of retinal

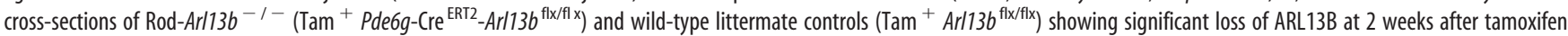

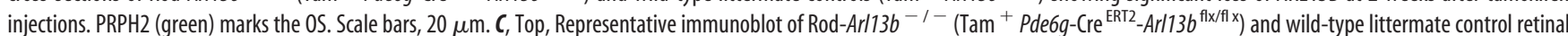
lysates $\left(\operatorname{Tam}^{+}\right.$Ar/136 $b^{\text {flx/flix }}$ ) of animals 2 weeks after tamoxifen-induced ARL13B deletion probed for ARL13B. GAPDH serves as loading control. C, Bottom, Quantification of ARL3B protein ( $n=3$ ) normalized against GAPDH. Data are represented as mean \pm SEM. ${ }^{* * *} p=0.0003$ as determined by Student's $t$ test.

differences in rod photoresponse between tamoxifen-injected Pde6g-Cre ${ }^{\text {ERT2 }}$-Arl13b ${ }^{\text {flx/fl x }}$ mutants ( Tam $^{+}$Rod-Arl13b $b^{-1-}$ ) and their wild-type littermate controls, including experimental animals to which tamoxifen was not administered (i.e., Tam ${ }^{-}$ Pde6g-Cre ${ }^{\text {ERT2 }}-A r l 13 b^{\text {flx/fl } x}$; Fig. $7 A$ ). However, a reduction in scotopic (rod) photoresponse occurred at 3 weeks, leading to complete ablation of photoresponse 5 weeks after injections (Fig. $7 A$ ). The photopic photoresponses were also severely affected 5 weeks after injections (data not shown). To eliminate the possi- bility that tamoxifen could lead to photoreceptor toxicity, thus affecting ERG responses, we administered tamoxifen in wild-type littermate controls and observed no changes in rod photoresponse up to 5 and 9 weeks after intraperitoneal injection (Fig. $7 A)$. We confirmed significant reduction of ARL13B in RodArl13b $b^{-1-}$ animals ( Tam $^{+}$Pde6g-Cre ${ }^{\text {ERT2 }}-A r l 13 b^{\text {flx/flx }}$ ) by immunohistochemical analysis on retinal cross-sections obtained 2 weeks after tamoxifen injections and by immunoblotting (Fig. $7 B, C ; 90 \%$ reduction for $\mathrm{ARL} 13 \mathrm{~B}, p=0.0003, n=3)$. Our results 
show that the absence of ARL13B in adult rods leads to rapid decline in photoreceptor viability and function.

\section{ARL13B is required for trafficking of rhodopsin}

Due to ARL13B's role as a GEF for ARL3, we speculated that prenylated cargo would be mislocalized after removal of ARL13B. At 2 weeks after tamoxifen injections, when rod photoresponse was unaltered (Fig. $7 A$ ), $\mathrm{Tam}^{+}$Rod-Arl13b ${ }^{-1-}$ retinal crosssections stained against PDE6 $\beta$ revealed small puncta in the photoreceptor IS (Fig. 8A, arrowheads). This finding is reminiscent of PDE6 $\beta$ accumulation in ARL3 dominant-active transgenic animal models (Wright et al., 2016). However, this defect was specific for PDE6 because we observed normal OS localization of prenylated rhodopsin kinase (GRK1) (data not shown). Interestingly, at 2 weeks after tamoxifen injections, rhodopsin was mislocalized to the IS and ONL (Fig. 8A). However, we observed no mislocalization of rod transducin or CNGA1 (data not shown). Furthermore, ultrastructural analysis of $\mathrm{Tam}^{+}{ }^{+}$Rod-Arl13b ${ }^{-1-} 2$ weeks after tamoxifen-induced deletion of ARL13B showed accumulation of vesicles within the photoreceptor OSs (Fig. $8 B$, red arrows), reminiscent of what was seen in Ret-Arl13B $B^{-1-}$ photoreceptors. More strikingly, 5 weeks after tamoxifen-induced deletion of ARL13B, the majority of photoreceptor cells were lost (Fig. 8C). Together, our data show ARL13B is needed for the maintenance of normal trafficking of OS proteins in adult rod photoreceptor cells.

\section{ARL13B is needed for the maintenance of the rod photoreceptor axoneme and IFT88 transport}

To further investigate the role of ARL13B in photoreceptor axonemal structure, we performed immunofluorescence imaging of lightly fixed retinal cross-sections of Tam ${ }^{+}$Rod-Arll3b $b^{-1-}$ animals at 2 weeks after tamoxifen injections and their wild-type littermate controls. We observed no significant changes in the immunostaining for both tubulin glutamylation $(1.24 \pm 0.02$ $\mu \mathrm{m}, n=300$ in littermate controls; $1.31 \pm 0.01 \mu \mathrm{m}, n=311$ in Rod-Arl13b $\left.b^{-1-;} p=0.004\right)$ and acetylation $(1.54 \pm 0.02 \mu \mathrm{m}$, $n=309$ in littermate controls; $1.66 \pm 0.02 \mu \mathrm{m}, n=358$ in Rod-Arl13b $\left.{ }^{-1-;} p=0.0002\right) 2$ weeks after tamoxifen injections (Fig. 9A,B). Interestingly, length measurements taken for immunostaining of RP1 protein, a microtubule-associated protein known to stain the photoreceptor axoneme, showed a significant length reduction in Tam ${ }^{+}$Rod-Arl13b $b^{-1-}$ mutants 2 weeks after tamoxifen injections (Fig. 9A; $3.38 \pm 0.05 \mu \mathrm{m}, n=322$ in littermate controls; $1.9 \pm 0.03 \mu \mathrm{m}, n=320$ in Rod-Arl13b ${ }^{-1-;} p=$ 0.0001 ). To further corroborate our findings, immunohistochemical analysis of MAK, a kinase normally found enriched in the photoreceptor axoneme, revealed significantly reduced immunostaining 2 weeks after tamoxifen injections in $\mathrm{Tam}^{+}$RodArl13b $b^{-1-}$ retinas (Fig. 9C; $2.80 \pm 0.05 \mu \mathrm{m}, n=305$ in littermate controls; $1.62 \pm 0.03 \mu \mathrm{m}, n=313$ in Rod-Arl13b ${ }^{-1-}$; $p=0.0001)$ (Omori et al., 2010).

In primary cilia, the bidirectional transport of proteins is mediated by the intraflagellar transport complex (IFT). Previous reports show accumulation of IFT-A and IFT-B proteins, specifically IFT88 and IFT40 subunits at the ciliary tip in ARL13B-null RPE cell lines (Nozaki et al., 2017). To establish whether the IFT complex is affected in photoreceptors lacking ARL13B, we performed immunohistochemical analysis of retinal cross-sections of Tam ${ }^{+}$Rod-Arll3b $b^{-1-}$ animals 2 weeks after tamoxifen injections and their wild-type littermate controls (Fig. 9B). In wildtype photoreceptors, IFT88 labeled both the proximal IS and distal OS ends of the photoreceptor connecting cilia (Fig. $9 B$, white arrowheads) (Pazour et al., 2002). Interestingly, similar to the phenotype observed in RPE cell lines, IFT88 accumulated in the distal segment of the photoreceptor connecting cilia with loss of immnunoreactivity at the proximal segment of the photoreceptor connecting cilia (Fig. $9 B$, white arrows). In addition, we observed mislocalization of IFT88 to the IS 2 weeks after ARL13B ablation (Fig. 9B). These results suggest that retrograde trafficking of IFT88-dependent cargoes could be affected in the absence of ARL13B. Overall, our results show that ARL13B is needed for the maintenance of photoreceptor axonemes in the adult retina.

\section{Discussion}

In this study, we sought to understand the role of ARL13B in photoreceptor cells. Intriguingly, global ablation of ARL13B in mice leads to embryonic lethality and anophthalmia (Caspary et al., 2007). Embryonic deletion of ARL13B led to proliferation defects in the developing retina. Ablation of ARL13B also resulted in defective morphogenesis of OS discs and rapid photoreceptor loss (Hanke-Gogokhia et al., 2017). In support of these findings, photoresponses were absent at any age tested in this animal model (Hanke-Gogokhia et al., 2017). Additionally, pan-retina ARL13B knock-outs displayed higher ratios of displaced basal bodies compared with wild-type littermates. The deletion of ARL13B in adult rod photoreceptors resulted in abrogation of photoreceptor function and severe retinal degeneration. We observed impaired transport of rhodopsin and prenylated PDE6 $\beta$, as well as the accumulation of intraflagellar transport complex protein-88 (IFT88). Overall, our models show the need for ARL13B throughout the development and maintenance of photoreceptor cells. During the preparation of this manuscript, a similar study was performed on ARL13B in murine photoreceptors (Hanke-Gogokhia et al., 2017). Our investigation was able to reproduce the main findings of the alternate study as well as introduce novel findings on the role of ARL13B in ciliated photoreceptor neurons. Figure 10 contains an overall schematic summary of the most important results observed in ARL13B-null retina at different stages.

The embryonic removal of ARL13B did not affect retinal lamination. However, we detected reduced proliferation of retinal progenitor cells (RPCs) using two independent markers (Fig. 3), resulting in reduced retinal thickness and photoreceptor nuclei layers at P5 (Fig. 2). Additionally, we observed reduction in natural retinal apoptosis at P5. We attribute reduction in apoptosis due to the lower number of proliferating cells present in ARL13Bnull retina. These findings suggest that the defect in the absence of ARL13B is in proliferation of precursors, not in a stimulation of their death. Our results are supported by studies showing slower proliferation rates in hennin mutant embryos and immortalized mouse embryonic fibroblast (HNN) cell lines, respectively (Pruski et al., 2016). Several lines of evidence have demonstrated that the Sonic Hedgehog pathway (SHH) is an extrinsic regulator of progenitor cell proliferation and differentiation in the neural retina (Dakubo and Wallace, 2004; Moshiri et al., 2005; Wall et al., 2009). At present, the mechanism behind reduced cell proliferation in the absence of ARL13B is not understood. However, previous reports have found that the absence of ARL13B and subsequent dysregulated $\mathrm{SHH}$ signaling leads to defects in neural tube patterning of ARL13B mutant embryos (Horner and Caspary, 2011; Larkins et al., 2011; Mariani et al., 2016). It is therefore possible that the defects in proliferation that we observed in Ret-Arll3b $b^{-1-}$ mutants could be in part due to dysregulated SHH detection by the RPCs that are still undergoing division during early postnatal development. Conversely, abnormal cell 
A
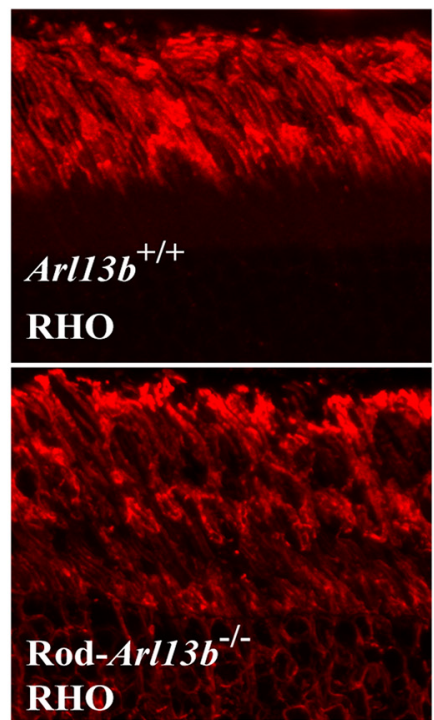
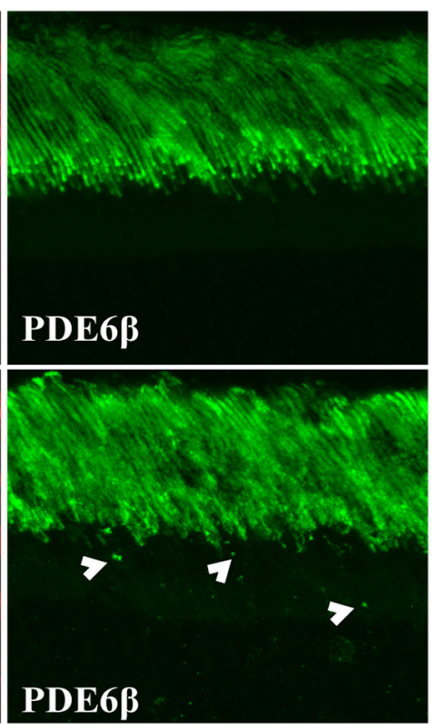
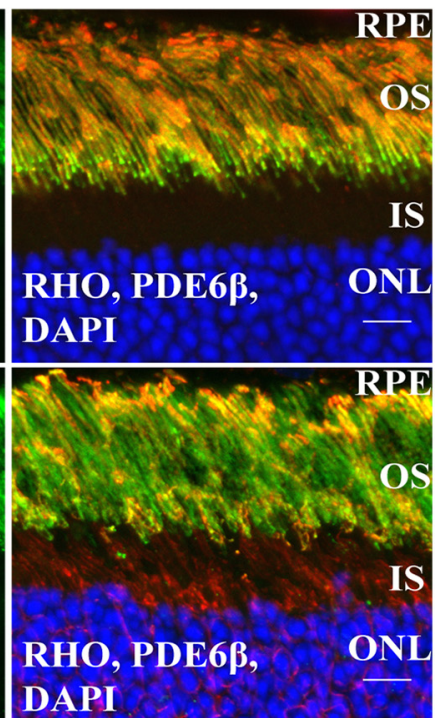

B

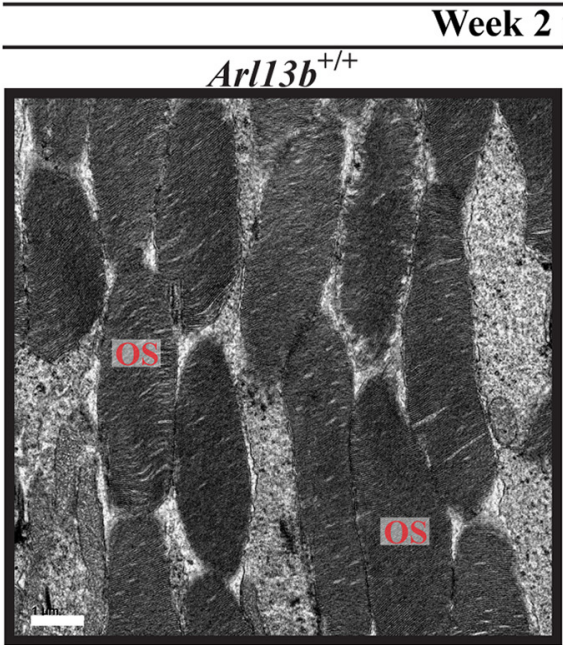

post-injection

$\operatorname{Rod}-A r l 13 b^{-/-}$

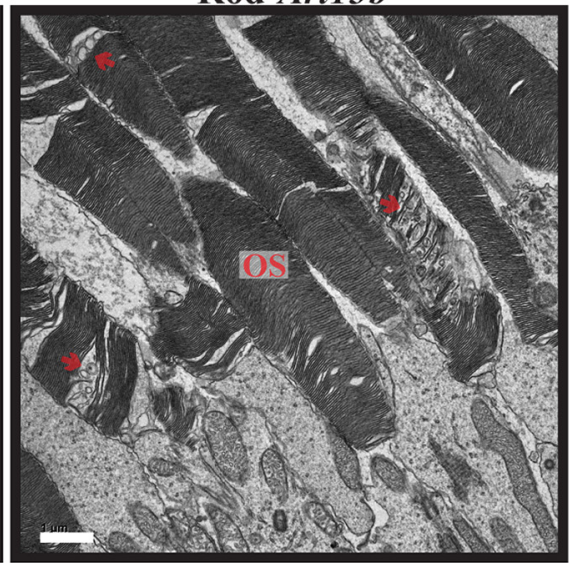

C

\section{Week 5 post-injection}
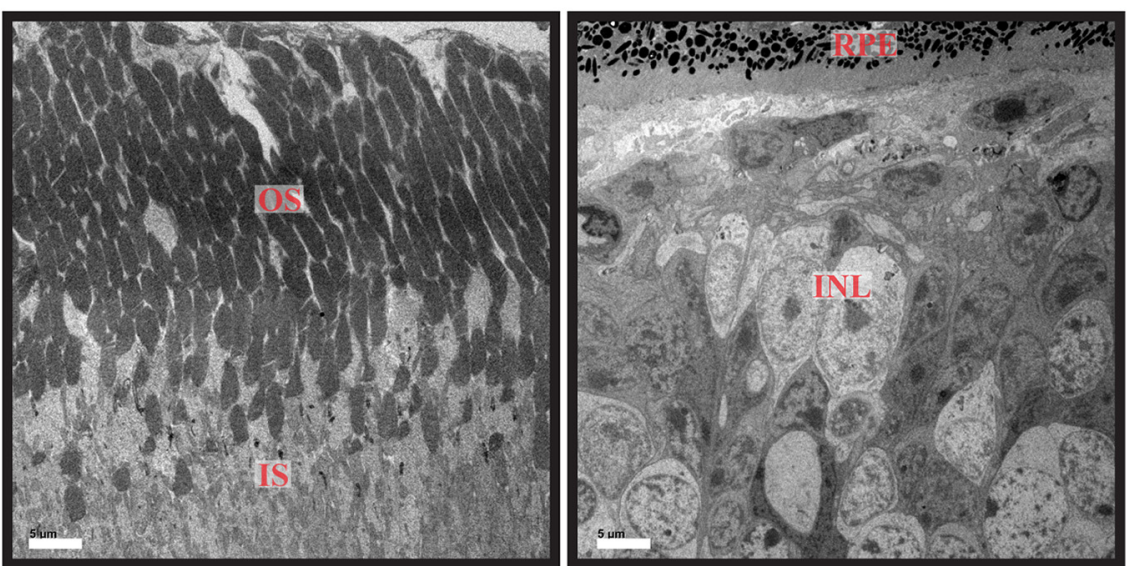

Figure 8. Rhodopsin is mislocalized after deletion of ARL13B in mature rod photoreceptors. $\boldsymbol{A}$, Retinal cross-sections of Rod-Arl136 $b^{-1-}$ and wild-type littermate controls 2 weeks after tamoxifen injection stained with antibodies against rhodopsin (red) and PDE6 $\beta$ (green). Punctate pattern of mislocalized PDE6 $\beta$ is indicated by white arrowheads. $\boldsymbol{B}$, Left, Electron micrographs of Rod-Arl136 ${ }^{-1-}$ and wild-type littermate controls 2 weeks after tamoxifen injections showing normal elaborated OS (left) and the initial stages of vesicle formation within 0S (right, red arrows) after ARL13B deletion. Scale bar, $1 \mu \mathrm{m}$. C, TEM images of wild-type littermate controls (left) and Rod-Arl136 ${ }^{-1-}$ (right) showing severe photoreceptor degeneration 5 weeks after tamoxifeninduced ARL13B ablation. Scale bar, $5 \mu \mathrm{m}$. 
A

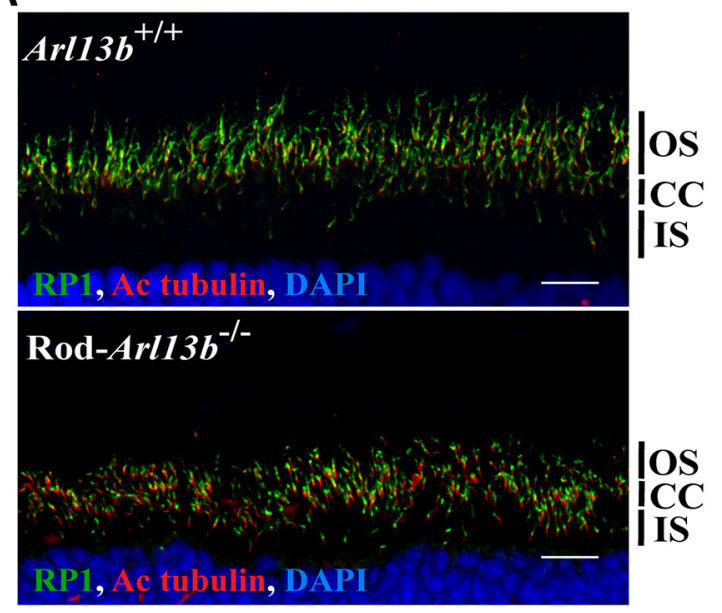

B
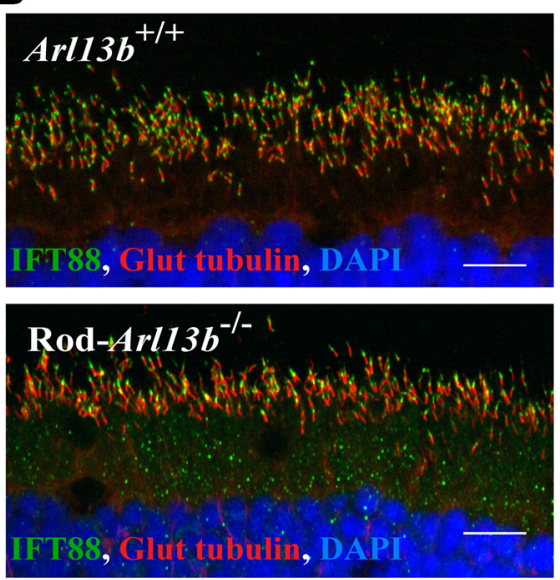

\section{C}
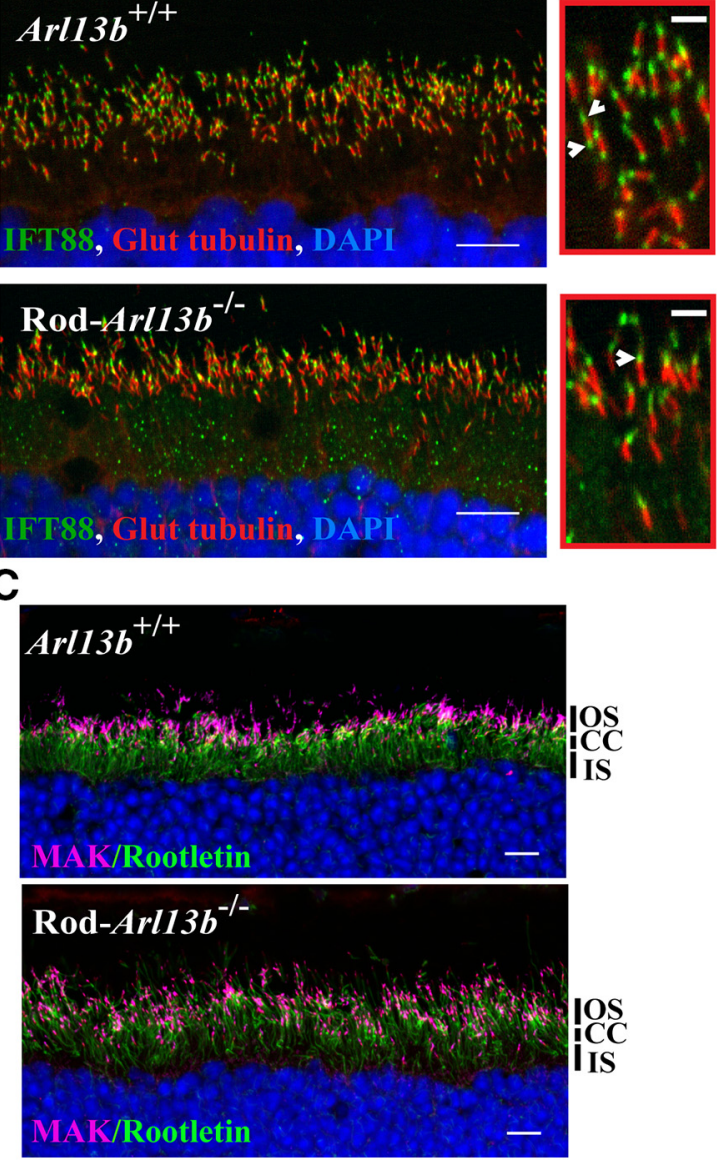
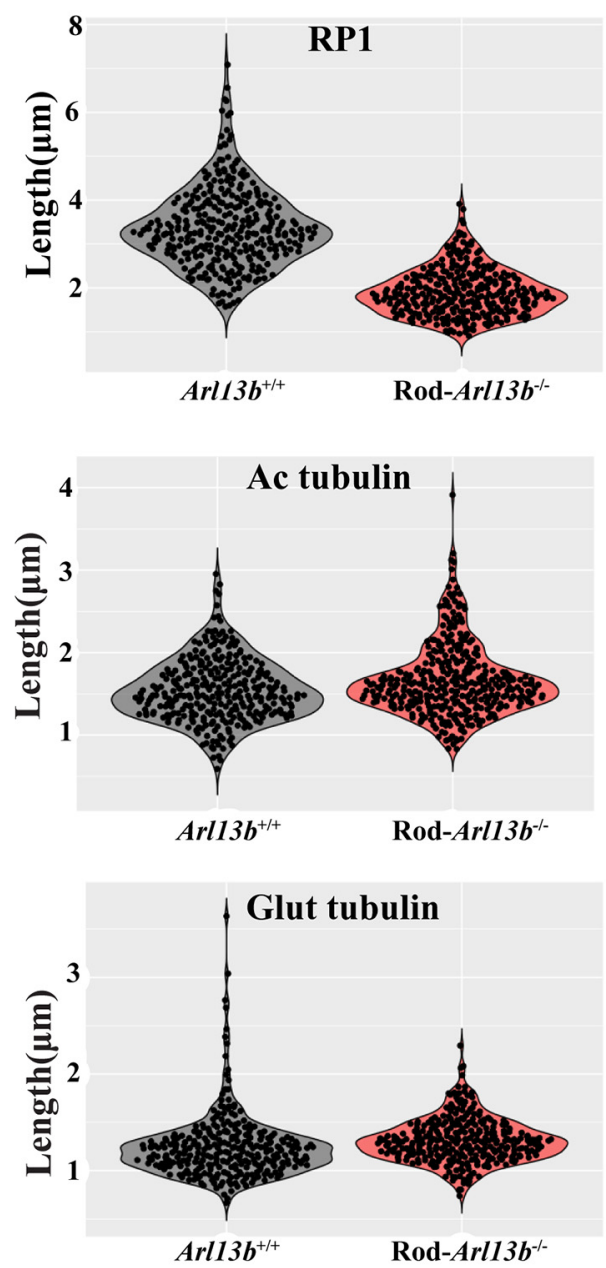

Figure 9. Altered axonemal length after elimination of ARL13B. A, Left, Immunofluorescence staining of cross-sections from Rod-Arl13b $b^{-1-}$ and wild-type littermate controls with axonemal marker RP1 (green) 2 weeks after tamoxifen injections. (Acetylated tubulin = connecting cilium marker, red). Scale bars, $10 \mu \mathrm{m}$. Right, Violin plots representing overall distribution of length measurements for RP1 and acetylated tubulin ( $n=300$ cilia pooled from 3 animals). B, Left, Immunohistochemistry of cross-sections from Rod-Arl13b $b^{-} /-$and wild-type littermate controls depicting IFT88 and connecting cilia marker glutamylated tubulin at 2 weeks after tamoxifen injections. Scale bars, $10 \mu \mathrm{m}$. Top red box, Representative immunofluorescence staining of IFT88 in wild-type retinal sections observed as two puncta at the basal and apical sides of the connecting cilium zone (arrowheads). In contrast, bottom red box shows representative immunofluorescence staining of IFT88 in Rod-Arl136 $b^{-1-}$ animals 2 weeks after tamoxifen injections observed as single puncta in the apical side of the connecting cilium zone. Scale bars, $2 \mu \mathrm{m}$. $\boldsymbol{B}$, Right, Violin plots representing overall distribution of length measurements for glutamylated tubulin ( $n=300$ pooled from 3 animals). C, Left, Retinal cross-sections from Rod-Arl13b ${ }^{-/-}$(tamoxifen-injected PDE6g-Cre ${ }^{\text {ERT2}}$-Arl13b $b^{\text {flx/flx }}$ animals) and wild-type littermate controls stained with antibody against axonemal marker MAK (cyan) and the IS marker rootletin (green). Scale bar, $10 \mu \mathrm{m}$. CC, Connecting cilia. Right, Violin plots representing overall distribution of length measurements for MAK ( $n=300$ cilia pooled from 3 animals).

proliferation was not observed in the neural tube of $A r l 13 b^{\text {hennin }}$ mutants during embryogenesis (Caspary et al., 2007). One possible explanation for the difference is the type of assay used in each study used to determine proliferation. Additionally, it is possible that the proliferation defects detected in the absence of ARL13B are likely dependent on the tissue, time of development, and the organism studied. It is worth emphasizing the phenotypic variance of ARL13B deletion observed across tissues and organ- 
A

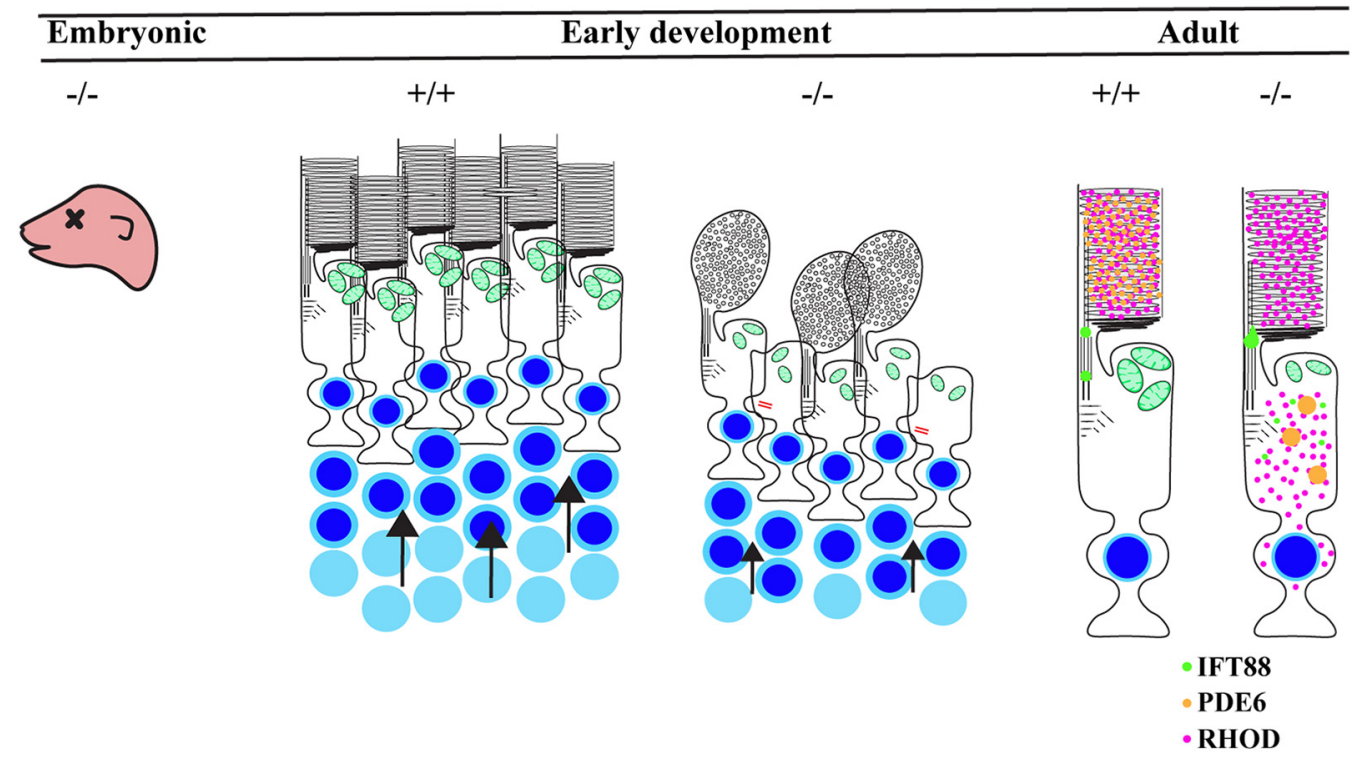

B

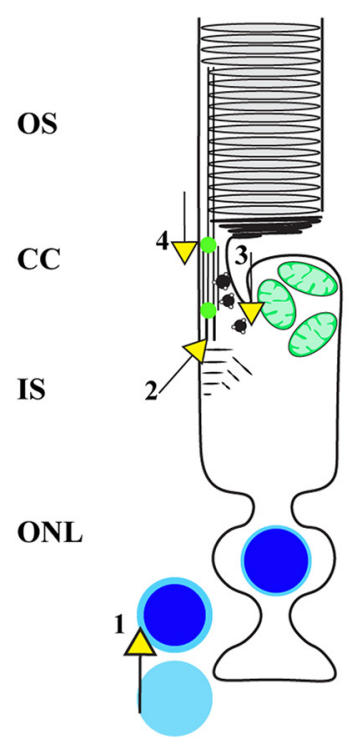

Figure 10. Summary of role for ARL13B in the retina. A, Scheme illustrating the need for ARL13B at different time points throughout murine retinal development: complete knock-out (hennin mutants) exhibited anophthlamia. Embryonic deletion of ARL13B in the retina resulted in decreased photoreceptor proliferation, basal body mislocalization, aberrant or no 0S disc formation accompanied by vesiculation, and impaired cilium growth. In fully developed rod photoreceptor cells (P60), 2 weeks after ARL13B-induced ablation, growth of the axoneme was impaired, IFT88 stalled, and PDE6 and rhodopsin mislocalized to the IS. B, Scheme illustrating the potential roles for ARL13B in photoreceptor neurons. (1) Proliferation signaling and/or detection, (2) basal body polarization, (3) repression of extracellular vesicles during $0 S$ disc formation, and (4) regulator of protein trafficking in ciliated photoreceptors.

isms. For instance, ARL13B deletion in the retina of zebrafish models leads to a slower photoreceptor degeneration phenotype compared with the rapid cell death observed in murine models (Song et al., 2016). Together, our results show ARL13B to be an essential player in murine retinal development.

Cilia development (ciliogenesis) is similar between primary cilia and photoreceptors in that both start with the mother and daughter centriole (basal bodies) adhering to what is termed a "ciliary vesicle" that docks to the apical plasma membrane, thus allowing microtubule extension (axonemal extension) to commence (Sedmak and Wolfrum, 2010; Pearring et al., 2013). In the absence of ARL13B, we observed a higher incidence of basal bodies that failed to dock to the apical side of the photoreceptor IS in the developing retina (Fig. $6 A-E$ ). It is likely that the aberrations in basal body positioning observed in photoreceptors lacking ARL13B is a contributing factor to the impaired ciliogenesis (or OS development) observed in ARL13B-null photoreceptors (Fig. 5).

The mechanisms behind photoreceptor OS morphogenesis remain one of the most perplexing topics in photoreceptor biology. ARL13B-null retina displayed little to no OS development; connecting cilia produced only OS rudiments that contained membrane vesicles but no membranous discs (Fig. 5). We attribute the loss of ERG responses to the absence of the membranous 
discs that host the phototransduction cascade machinery necessary for visual transduction (Fig. 2). Previous reports have found that ARL13B associates with membranes via palmitoyl lipid anchors in primary cilia and our data show enrichment of ARL13B in rod OSs (Fig. 1) (Cevik et al., 2010; Roy et al., 2017). Interestingly, ARL13B contains a "VxPx" motif in its C termini (Mariani et al., 2016). This motif is also present in various OS-resident proteins including rhodopsin and PRPH2 and is thought to be essential for their targeting to the OS (Deretic et al., 1998; Tam et al., 2004; Pearring et al., 2013). Additionally, ARL13B has been shown to be required for elongation of primary cilia through aiding in ciliary membrane protrusion by an unknown mechanism (Lu et al., 2015). These findings suggest that ARL13B could play an important structural/morphological role in generation of the OS by its association with photoreceptor membranes (Fig. 1). In the absence of ARL13B, we observed extracellular vesicles (EVs), similar to those observed in PRPH2- and BBS8-null retinas (Fig. 5) (Salinas et al., 2017; Dilan et al., 2018). It is thought that the EV-suppressing pathway promoted by PRPH2 permits the formation of photoreceptor OS discs (Molday and Goldberg, 2017; Salinas et al., 2017). It is possible that ARL13B, along with other key players, act synergistically in photoreceptor OS development by suppressing the "EV-release" pathway and aiding in ciliary membrane protrusion. Current studies are focused on further characterizing the involvement of ARL13B in OS morphogenesis and determining the subcellular localization of ARL13B within the photoreceptor OS.

Embryonic deletion of ARL13B resulted in proliferation defects, aberrant photoreceptor ciliogenesis, and disrupted OS morphogenesis. Remarkably, removal of ARL13B in adult rods led to abolished photoreceptor function (Fig. 7). Additionally, 2 weeks after ARL13B deletion, when rod photoresponse is comparable between ARL13B-null rods and littermate controls, we observed vesicles accumulating within the photoreceptor OS (Fig. 8B). Moreover, we observed mislocalization of rhodopsin to the photoreceptor IS and ONL, as well as accumulation of IFT88 to the apical tip of the connecting cilia (Figs. 8A, 9B). The bidirectional transport of protein cargoes along the ciliary axoneme is mediated by the IFT, which is composed of two multiprotein subcomplexes, IFT-A and IFT-B (Lechtreck, 2015; Taschner and Lorentzen, 2016). The IFT complex also aids in the elongation of the ciliary axoneme by concentrating tubulin to the ciliary tip (Harris et al., 2018). ARL13B directly interacts with members of the IFT-B subcomplex, which mediates the anterograde transport of proteins from the base to the ciliary tip (Cevik et al., 2013; Nozaki et al., 2017). Our findings suggest possible alterations of ciliary protein trafficking (i.e., rhodopsin) and/or impaired retrograde transport in ARL13B-null photoreceptors. It is possible the axonemal defects (i.e., shortening) that we observed 2 weeks after rod-specific tamoxifen-induced deletion of ARL13B is a result of the mislocalization of IFT88 (Fig. 9). Mice carrying a mutation in the IFT88 subunit ( $\mathrm{gg737/Ift88)}$ have been reported to develop vesiculated photoreceptor OSs, extracellular vesicle formation (ectosomes), and rhodopsin mislocalization (Pazour et al., 2002). The phenotypes observed in ARL13B-depleted adult rod photoreceptors resemble the reported phenotypes of $\mathrm{Tg} 737 /$ Ift 88 animals. Nevertheless, we cannot solely attribute the abnormalities observed in our ARL13B animal models to defects in the IFT complex. Previous reports show that ARL13B aids as the GEF for ARL3 (Gotthardt et al., 2015). Active ARL3 is needed for the release of PDE6 $\delta$-bound prenylated cargo proteins including PDE6 to the photoreceptor OS (Wright et al., 2016). It is likely that the defects observed in ARL13B-deficient retinas, such as
PDE6 mislocalization, are a result of misregulation of ARL3 activity (Fig. 8A). It is important to note that localization of OSresident proteins such as GRK1, CNGA1, or Transducin was unaffected (data not shown). The primary defect in the ARL13Bnull retinas was impaired OS development. Interestingly, we observed areas of selective loss of PDE6 in the retina where the majority of opsin was localized to the OS (Fig. $4 B$ ). These findings lend support to the idea that GEF activity of ARL13B is needed for trafficking and/or biosynthesis of prenylated PDE6 (HankeGogokhia et al., 2017). In conclusion, our study documents the essential role for ARL13B in early photoreceptor development, function, and maintenance. Therefore, identification of the phenotypical events that ARL13B and its multiple protein interactors participate in photoreceptor neurons is a subject that will be addressed in future studies.

\section{References}

Arikawa K, Williams DS (1993) Acetylated alpha-tubulin in the connecting cilium of developing rat photoreceptors. Invest Ophthalmol Vis Sci 34: 2145-2149. Medline

Bay SN, Long AB, Caspary T (2018) Disruption of the ciliary GTPase Arl13b suppresses sonic hedgehog overactivation and inhibits medulloblastoma formation. Proc Natl Acad Sci U S A 115:1570-1575. CrossRef Medline

Bishop AL, Hall A (2000) Rho GTPases and their effector proteins. Biochem J 348:241-255. CrossRef Medline

Cantagrel V, Silhavy JL, Bielas SL, Swistun D, Marsh SE, Bertrand JY, Audollent S, Attié-Bitach T, Holden KR, Dobyns WB, Traver D, Al-Gazali L, Ali BR, Lindner TH, Caspary T, Otto EA, Hildebrandt F, Glass IA, Logan CV, Johnson CA, et al. (2008) Mutations in the cilia gene ARL13B lead to the classical form of Joubert syndrome. Am J Hum Genet 83:170-179. CrossRef Medline

Caspary T, Larkins CE, Anderson KV (2007) The graded response to sonic hedgehog depends on cilia architecture. Dev Cell 12:767-778. CrossRef Medline

Cevik S, Sanders AA, Van Wijk E, Boldt K, Clarke L, van Reeuwijk J, Hori Y, Horn N, Hetterschijt L, Wdowicz A, Mullins A, Kida K, Kaplan OI, van Beersum SE, Man Wu K, Letteboer SJ, Mans DA, Katada T, Kontani K, Ueffing M, et al. (2013) Active transport and diffusion barriers restrict Joubert syndrome-associated ARL13B/ARL-13 to an Inv-like ciliary membrane subdomain. PLoS Genet 9:e1003977. CrossRef Medline

Cevik S, Hori Y, Kaplan OI, Kida K, Toivenon T, Foley-Fisher C, Cottell D, Katada T, Kontani K, Blacque OE (2010) Joubert syndrome Arl13b functions at ciliary membranes and stabilizes protein transport in Caenorhabditis elegans. J Cell Biol 188:953-969. CrossRef Medline

Cherfils J, Zeghouf M (2013) Regulation of small GTPases by GEFs, GAPs, and GDIs. Physiol Rev 93:269-309. CrossRef Medline

Dakubo GD, Wallace VA (2004) Hedgehogs and retinal ganglion cells: organizers of the mammalian retina. Neuroreport 15:479-482. CrossRef Medline

Deretic D, Schmerl S, Hargrave PA, Arendt A, McDowell JH (1998) Regulation of sorting and post-golgi trafficking of rhodopsin by its C-terminal sequence QVS(A)PA. Proc Natl Acad Sci U S A 95:10620-10625. CrossRef Medline

Dilan TL, Singh RK, Saravanan T, Moye A, Goldberg AFX, Stoilov P, Ramamurthy V (2018) Bardet-Biedl syndrome-8 (BBS8) protein is crucial for the development of outer segments in photoreceptor neurons. Hum Mol Genet 27:283-294. CrossRef Medline

Furuta Y, Lagutin O, Hogan BL, Oliver GC (2000) Retina- and ventral forebrain-specific cre recombinase activity in transgenic mice. Genesis 26:130-132. CrossRef Medline

Giménez E, Montoliu L (2001) A simple polymerase chain reaction assay for genotyping the retinal degeneration mutation $(\mathrm{Pdeb}(\mathrm{rdl}))$ in $\mathrm{FVB} / \mathrm{N}$ derived transgenic mice. Lab Anim 35:153-156. CrossRef Medline

Goldberg AF, Ritter LM, Khattree N, Peachey NS, Fariss RN, Dang L, Yu M, Bottrell AR (2007) An intramembrane glutamic acid governs peripherin/rds function for photoreceptor disk morphogenesis. Invest Ophthalmol Vis Sci 48:2975-2986. CrossRef Medline

Gotthardt K, Lokaj M, Koerner C, Falk N, Gießl A, Wittinghofer A (2015) A G-protein activation cascade from Arl13B to Arl3 and implications for ciliary targeting of lipidated proteins. Elife 4:e11859. CrossRef Medline 
Hanke-Gogokhia C, Wu Z, Gerstner CD, Frederick JM, Zhang H, Baehr W (2016) Arf-like protein 3 (ARL3) regulates protein trafficking and ciliogenesis in mouse photoreceptors. J Biol Chem 291:7142-7155. CrossRef Medline

Hanke-Gogokhia C, Wu Z, Sharif A, Yazigi H, Frederick JM, Baehr W (2017) The guanine nucleotide exchange factor, Arf-like protein 13b, is essential for assembly of the mouse photoreceptor transition zone and outer segment. J Biol Chem 292:21442-21456. CrossRef Medline

Harris JA, Van De Weghe JM, Kubo T, Witman GB, Lechtreck K (2018) Diffusion rather than IFT provides most of the tubulin required for axonemal assembly. Available from https://www.biorxiv.org/content/ early/2018/02/20/268573.

Hendzel MJ, Wei Y, Mancini MA, Van Hooser A, Ranalli T, Brinkley BR, Bazett-Jones DP, Allis CD (1997) Mitosis-specific phosphorylation of histone $\mathrm{H} 3$ initiates primarily within pericentromeric heterochromatin during $G_{2}$ and spreads in an ordered fashion coincident with mitotic chromosome condensation. Chromosoma 106:348-360. CrossRef Medline

Hori Y, Kobayashi T, Kikko Y, Kontani K, Katada T (2008) Domain architecture of the atypical arf-family GTPase Arl13b involved in cilia formation. Biochem Biophys Res Commun 373:119-124. CrossRef Medline

Horner VL, Caspary T (2011) Disrupted dorsal neural tube BMP signaling in the cilia mutant Arl13b(hnn) stems from abnormal shh signaling. Dev Biol 355:43-54. CrossRef Medline

Hua K, Ferland RJ (2017) Fixation methods can differentially affect ciliary protein immunolabeling. Cilia 6:5. CrossRef Medline

Ismail SA, Chen YX, Miertzschke M, Vetter IR, Koerner C, Wittinghofer A (2012) Structural basis for Arl3-specific release of myristoylated ciliary cargo from UNC119. EMBO J 31:4085-4094. CrossRef Medline

Ivanova AA, Caspary T, Seyfried NT, Duong DM, West AB, Liu Z, Kahn RA (2017) Biochemical characterization of purified mammalian ARL13B protein indicates that it is an atypical GTPase and ARL3 guanine nucleotide exchange factor (GEF). J Biol Chem 292:11091-11108. CrossRef Medline

Koch SF, Tsai YT, Duong JK, Wu WH, Hsu CW, Wu WP, Bonet-Ponce L, Lin CS, Tsang SH (2015) Halting progressive neurodegeneration in advanced retinitis pigmentosa. J Clin Invest 125:3704-3713. CrossRef Medline

Larkins CE, Aviles GD, East MP, Kahn RA, Caspary T (2011) Arl13b regulates ciliogenesis and the dynamic localization of shh signaling proteins. Mol Biol Cell 22:4694-4703. CrossRef Medline

Lechtreck KF (2015) IFT-cargo interactions and protein transport in cilia. Trends Biochem Sci 40:765-778. CrossRef Medline

Li Y, Tian X, Ma M, Jerman S, Kong S, Somlo S, Sun Z (2016) Deletion of ADP ribosylation factor-like GTPase 13B leads to kidney cysts. J Am Soc Nephrol 27:3628-3638. CrossRef Medline

Liu Q, Zuo J, Pierce EA (2004) The retinitis pigmentosa 1 protein is a photoreceptor microtubule-associated protein. J Neurosci 24:6427-6436. CrossRef Medline

Lu H, Toh MT, Narasimhan V, Thamilselvam SK, Choksi SP, Roy S (2015) A function for the joubert syndrome protein Arl13b in ciliary membrane extension and ciliary length regulation. Dev Biol 397:225-236. CrossRef Medline

Malicki JJ, Johnson CA (2017) The cilium: cellular antenna and central processing unit. Trends Cell Biol 27:126-140. CrossRef Medline

Mariani LE, Bijlsma MF, Ivanova AI, Suciu SK, Kahn RA, Caspary T (2016) Arl13b regulates shh signaling from both inside and outside the cilium. Mol Biol Cell 27:3780-3790. CrossRef Medline

Mattapallil MJ, Wawrousek EF, Chan CC, Zhao H, Roychoudhury J, Ferguson TA, Caspi RR (2012) The Rd8 mutation of the Crbl gene is present in vendor lines of C57BL/6N mice and embryonic stem cells, and confounds ocular induced mutant phenotypes. Invest Ophthalmol Vis Sci 53:2921-2927. CrossRef Medline

Miertzschke M, Koerner C, Spoerner M, Wittinghofer A (2014) Structural insights into the small G-protein Arl13B and implications for joubert syndrome. Biochem J 457:301-311. CrossRef Medline

Molday RS, Goldberg AFX (2017) Peripherin diverts ciliary ectosome release to photoreceptor disc morphogenesis. J Cell Biol 216:1227-1229. CrossRef Medline

Mongan M, Wang J, Liu H, Fan Y, Jin C, Kao WY, Xia Y (2011) Loss of MAP3K1 enhances proliferation and apoptosis during retinal development. Development 138:4001-4012. CrossRef Medline

Moshiri A, McGuire CR, Reh TA (2005) Sonic hedgehog regulates prolifer- ation of the retinal ciliary marginal zone in posthatch chicks. Dev Dyn 233:66-75. CrossRef Medline

Nickell S, Park PS, Baumeister W, Palczewski K (2007) Three-dimensional architecture of murine rod outer segments determined by cryoelectron tomography. J Cell Biol 177:917-925. CrossRef Medline

Nozaki S, Katoh Y, Terada M, Michisaka S, Funabashi T, Takahashi S, Kontani K, Nakayama K (2017) Regulation of ciliary retrograde protein trafficking by the joubert syndrome proteins ARL13B and INPP5E. J Cell Sci 130:563-576. CrossRef Medline

Omori Y, Chaya T, Katoh K, Kajimura N, Sato S, Muraoka K, Ueno S, Koyasu T, Kondo M, Furukawa T (2010) Negative regulation of ciliary length by ciliary male germ cell-associated kinase (Mak) is required for retinal photoreceptor survival. Proc Natl Acad Sci U S A 107:22671-22676. CrossRef Medline

Pazour GJ, Baker SA, Deane JA, Cole DG, Dickert BL, Rosenbaum JL, Witman GB, Besharse JC (2002) The intraflagellar transport protein, IFT88, is essential for vertebrate photoreceptor assembly and maintenance. J Cell Biol 157:103-113. CrossRef Medline

Pearring JN, Salinas RY, Baker SA, Arshavsky VY (2013) Protein sorting, targeting and trafficking in photoreceptor cells. Prog Retin Eye Res 36: 24-51. CrossRef Medline

Pinto LH, Invergo B, Shimomura K, Takahashi JS, Troy JB (2007) Interpretation of the mouse electroretinogram. Doc Ophthalmol 115:127-136. CrossRef Medline

Portran D, Schaedel L, Xu Z, Théry M, Nachury MV (2017) Tubulin acetylation protects long-lived microtubules against mechanical aging. Nat Cell Biol 19:391-398. CrossRef Medline

Pruski M, Rajnicek A, Yang Z, Clancy H, Ding YQ, McCaig CD, Lang B (2016) The ciliary GTPase Arl13b regulates cell migration and cell cycle progression. Cell Adh Migr 10:393-405. CrossRef Medline

Quinteros Q, Benedetto ML, Maldonado MM, E ACVdP, Contin MA (2016) Electroretinography: a biopotential to assess the function/dysfunction of the retina. Journal of Physics: Conference Series 705:012053. CrossRef

Rakshit T, Senapati S, Sinha S, Whited AM, Park PS (2015) rhodopsin forms nanodomains in rod outer segment disc membranes of the cold-blooded Xenopus laevis. PLoS One 10:e0141114. CrossRef Medline

Ramamurthy V, Niemi GA, Reh TA, Hurley JB (2004) Leber congenital amaurosis linked to AIPL1: a mouse model reveals destabilization of cGMP phosphodiesterase. Proc Natl Acad Sci U S A 101:13897-13902. CrossRef Medline

Roy K, Jerman S, Jozsef L, McNamara T, Onyekaba G, Sun Z, Marin EP (2017) Palmitoylation of the ciliary GTPase ARL13b is necessary for its stability and its role in cilia formation. J Biol Chem 292:17703-17717. CrossRef Medline

Salinas RY, Pearring JN, Ding JD, Spencer WJ, Hao Y, Arshavsky VY (2017) Photoreceptor discs form through peripherin-dependent suppression of ciliary ectosome release. J Cell Biol 216:1489-1499. CrossRef Medline

Sedmak T, Wolfrum U (2010) Intraflagellar transport molecules in ciliary and nonciliary cells of the retina. J Cell Biol 189:171-186. CrossRef Medline

Skiba NP, Spencer WJ, Salinas RY, Lieu EC, Thompson JW, Arshavsky VY (2013) Proteomic identification of unique photoreceptor disc components reveals the presence of PRCD, a protein linked to retinal degeneration. J Proteome Res 12:3010-3018. CrossRef Medline

Song P, Dudinsky L, Fogerty J, Gaivin R, Perkins BD (2016) Arll3b interacts with Vangl2 to regulate cilia and photoreceptor outer segment length in zebrafish. Invest Ophthalmol Vis Sci 57:4517-4526. CrossRef Medline

Strom SP, Clark MJ, Martinez A, Garcia S, Abelazeem AA, Matynia A, Parikh S, Sullivan LS, Bowne SJ, Daiger SP, Gorin MB (2016) De novo occurrence of a variant in arl3 and apparent autosomal dominant transmission of retinitis pigmentosa. PLoS One 11:e0150944. CrossRef Medline

Su CY, Bay SN, Mariani LE, Hillman MJ, Caspary T (2012) Temporal deletion of Arl13b reveals that a mispatterned neural tube corrects cell fate over time. Development 139:4062-4071. CrossRef Medline

Suga A, Sadamoto K, Fujii M, Mandai M, Takahashi M (2014) Proliferation potential of Müller glia after retinal damage varies between mouse strains. PLoS One 9:e94556. CrossRef Medline

Sun Z, Amsterdam A, Pazour GJ, Cole DG, Miller MS, Hopkins N (2004) A genetic screen in zebrafish identifies cilia genes as a principal cause of cystic kidney. Development 131:4085-4093. CrossRef Medline 
Tam BM, Moritz OL, Papermaster DS (2004) The C terminus of peripherin/ rds participates in rod outer segment targeting and alignment of disk incisures. Mol Biol Cell 15:2027-2037. CrossRef Medline

Taschner M, Lorentzen E (2016) The intraflagellar transport machinery. Cold Spring Harb Perspect Biol 8:a028092. CrossRef Medline

Thomas S, Cantagrel V, Mariani L, Serre V, Lee JE, Elkhartoufi N, de Lonlay P, Desguerre I, Munnich A, Boddaert N, Lyonnet S, Vekemans M, Lisgo SN, Caspary T, Gleeson J, Attié-Bitach T (2015) Identification of a novel ARL13B variant in a joubert syndrome-affected patient with retinal impairment and obesity. Eur J Hum Genet 23:621-627. CrossRef Medline

Vardi N (1998) Alpha subunit of go localizes in the dendritic tips of ON bipolar cells. J Comp Neurol 395:43-52. CrossRef Medline
Wall DS, Mears AJ, McNeill B, Mazerolle C, Thurig S, Wang Y, Kageyama R, Wallace VA (2009) Progenitor cell proliferation in the retina is dependent on notch-independent sonic hedgehog/Hes1 activity. J Cell Biol 184: 101-112. CrossRef Medline

Wolfrum U, Giessl A, Pulvermuller A (2002) Centrins, a novel group of $\mathrm{Ca}^{2+}$-binding proteins in vertebrate photoreceptor cells. Advances in experimental medicine and biology 514:155-178. Medline

Wright ZC, Singh RK, Alpino R, Goldberg AF, Sokolov M, Ramamurthy V (2016) ARL3 regulates trafficking of prenylated phototransduction proteins to the rod outer segment. Hum Mol Genet 25:2031-2044. CrossRef Medline

Zhang Q, Li Y, Zhang Y, Torres VE, Harris PC, Ling K, Hu J (2016) GTPbinding of ARL-3 is activated by ARL-13 as a GEF and stabilized by UNC-119. Sci Rep 6:24534. CrossRef Medline 